\title{
CIEN AÑOS DE INVESTIGACIÓN SOCIOLÓGICA SOBRE ESPAÑA
}

\author{
Jesús M. de Miguel \\ Universidad de Barcelona \\ E-mail: demiguel@eco.ub.es
}

\begin{abstract}
RESUMEN
La Sociología española nace y se desarrolla en el siglo XX. Se cumplen cuarenta años desde el primer recuento de la «Sociología en España» realizado de forma excelente por Enrique Gómez Arboleya (1959). En el presente artículo se presenta una selección de los mejores estudios sobre la sociedad española desde dentro y fuera del país, durante todo el siglo XX. El desarrollo de la Sociología es un proceso que debe estudiarse paralelo a la transformación de la estructura social de España, y a los procesos de cambio social. La hipótesis es que el conocimiento refleja la propia sociedad y, al mismo tiempo, trata de cambiarla. En la última parte del artículo se resumen, además, las principales polémicas o debates sociológicos que han ocurrido durante el siglo XX. Todavía está por escribir un estudio sobre las experiencias de cambio social que se han producido en España gracias a la Sociología ${ }^{1}$.
\end{abstract}

${ }^{1}$ El presente artículo se presentó en el seminario de profesores del Departamento de Sociología de la Universidad Pública de Navarra, el 10 de diciembre de 1998, en el cincuenta aniversario de la Declaración Universal de los Derechos Humanos. Muchas gracias a Bernabé Sarabia y al Departamento de la Universidad Pública de Navarra, por sus ideas y sugerencias. Un análisis global —así como las citas bibliográficas exactas- puede verse en Jesús M. DE MigUEL, Estructura y cambio social en España (Madrid: Alianza Editorial, 1998), 681 pp. Debe consultarse, además, Bernabé SARABIA y Juan ZarCo, Metodología cualitativa en España (Madrid: Cuadernos Metodológicos número 22, Centro de Investigaciones Sociologicas, 1997), 127 pp. Para cualquier comentario adicional sobre el presente artículo se puede utilizar la dirección: Jesús M. de Miguel, Director del Departamento de Sociología, Universidad de Barcelona, Avenida Diagonal, 690, 08034 Barcelona, tel. 9340214 06, y correo electrónico: demiguel@eco.ub.es. 
Desde hace décadas, y aun siglos, España atrae la atención de viajeros extranjeros ${ }^{2}$. Suelen ser visiones críticas o románticas. Otras veces la observación desde dentro se publica fuera, como en las famosas Letters from Spain, de José Blanco White, fechadas en Chelsea en el verano de 1822, o las Cartas finlandesas de Ángel Ganivet al final del siglo XIX, con un contenido más político. Al primero le cuesta la excomunión; al segundo, el suicidio. Pero, salvo esos libros de viajes o cartas ficticias, no es hasta la segunda mitad del siglo XX que el análisis de la sociedad española genera cientos de libros y miles de artículos. Desde la Guerra Civil (1936-1939) la investigación sobre la estructura social y los procesos de cambio que se producen en España es creciente. Es importante seleccionar las contribuciones más relevantes y que, a su vez, tienen un impacto mayor en los análisis posteriores. Muchos estudios son realizados dentro de España, pero hay también varias escuelas de historiadores, hispanistas, casas editoriales y Departamentos universitarios en el extranjero que cumplen un papel importante en el proceso de conocimiento sobre la realidad social española. Además de los/as sociólogos, científicos, políticos e historiadores, durante el siglo XX España es un país predilecto para trabajo de campo y estudios antropológicos. Los/as investigadores locales aprenden de las contribuciones realizadas desde otros países.

Terminada la Guerra Civil, los años cuarenta, sobre todo los primeros, se suelen denominar «los años del hambre». Durante esa época la producción investigadora social es mínima. Las cuestiones planteadas por Ángel Ganivet en su Idearium español (1897), que se convierten en el manifiesto de toda la generación del 98; luego por José Ortega y Gasset en España invertebrada: Bosquejo de algunos pensamientos históricos (1921) y la generación de 1914, o por Salvador de Madariaga en su Spain (1930) — por poner tres ejemplos importantes-, quedan sin respuesta. Hay una cesura entre el pensamiento regeneracionista, krausista, e incluso el de la generación de 1898 y la producción sociológica, limitadísima, de las dos primeras décadas tras la guerra.

Hasta finales del siglo XIX la actitud de los intelectuales españoles sobre la investigación social es bastante negativa. Un ejemplo claro es el discurso de Antonio Cánovas del Castillo en su ingreso en la Real Academia de Ciencias Morales y Políticas, en 1881, y cuyo largo título es: Las últimas hipótesis de las Ciencias Naturales, no dan más firme fundamento a la Sociología que las creen-

${ }^{2}$ Los libros de viajes, como el de Joseph Townsend, A Journey Through Spain in the Years 1786 and 1787 (1792), suelen incluir un análisis de la estructura demográfica, social, y económica del país. El presente artículo está dedicado, con el máximo cariño sociológico, a Renata y James Fernández, de University of Chicago, por su contribución antropológica para entender España; y con el agradecimiento por las ideas y entusiasmo intelectual de los dos. Es un privilegio que scholars extranjeros como ellos dediquen su esfuerzo a enseñar e investigar España. 
cias, aún miradas también como hipótesis, en que los estudios sociológicos han sabido buscar sus cimientos hasta ahora (Cánovas 1881$)^{3}$. Sin embargo, al final del siglo XIX el regeneracionismo produce estudios sociales novedosos sobre pobreza, presos, delincuentes, jornaleros y, en general, sobre problemas sociales (Arenal 1895, 1897, por ejemplo). El libro básico del regeneracionismo es El problema nacional: Hechos, causas y remedios, de Ricardo Macías Picavea (1899) ${ }^{4}$.

La crisis de España se hace evidente al inicio del nuevo siglo con estudios como los de Joaquín Costa, Reconstrucción y europeización de España (1900) y Crisis politica de España: Doble llave al sepulcro del Cid (1914). Es importante José Ortega y Gasset con su Vieja y nueva política (1914). Los intelectuales replantean el carácter nacional español (Altamira 1902) y debaten obsesivamente sobre la «españolidad» en obras como la de Miguel de Unamuno, En torno al casticismo (1902). Hay toda una colección de estudios reformistas que incluyen los importantes estudios del Instituto de Reformas Sociales, como la Información sobre el trabajo en las minas (IRS 1910). Otros estudian la universidad (Giner de los Ríos 1916); realizan una primera encuesta a escolares, como Eugenio d'Ors (1921), o estudian el analfabetismo endémico del país (Luzuriaga 1926). Todos estos estudios regeneracionistas, krausistas, y reformistas tienen un interés sociológico considerable, pero son pronto olvidados. Queda, eso sí, la impronta de la generación del 98 en su versión literaria más rasgada, que alcanza hasta Trasuntos de España, de Azorín, en 19385. Pero nada comparable a la desgracia que supone la dictadura de Franco.

\section{LOS AÑOS DEL HAMBRE}

En 1939, al terminar la Guerra Civil, no hay dentro del país sociólogos críticos que analicen la estructura social y política de España. Apenas se permiten otros estudios que no sean demográficos pro-imperialistas. Una excepción llamativa es Esteban Pinilla de las Heras, quien durante su adolescencia y juventud en España (1935-1959) elabora un diario que posteriormente le sirve para escribir una autobiografía en base a esos cuadernos. Su casa de la calle Rocafort se convierte en un verdadero observatorio sociológico que analiza la estructura

3 Es curioso que uno de los primeros trabajos de Esteban Pinilla de las Heras, en 1948, es precisamente sobre "El pensamiento político de Cánovas», artículo objeto de una mención y premio en el concurso del cincuentenario de la muerte de Cánovas del Castillo, convocado por la revista Leonardo, las Ideas y las Formas y por el semanario Destino (publicado en este último, el 31 de enero de 1948). La polémica sigue, porque Salustiano del Campo publica un artículo sobre "Cánovas del Castillo y el nacimiento de la sociología española», en la sesión del 20 de mayo de 1997 en la Real Academia de Ciencias Morales y Políticas.

${ }^{4}$ Es interesante leer reflexiones autobiográficas de esos años en libros como Cartas de un joven español (1891-1908), de José Ortega y Gasset (no publicado hasta 1991).

5 El tema de España aparece en otras numerosas obras de Azorín, como El paisaje de España visto por los españoles, Una hora de España, Lecturas españolas, Vida de España, y España. 
social española con mirada inquieta, crítica e independiente. El libro aparece póstumamente (después de su muerte, en junio de 1994) con el título de La memoria inquieta: Autobiografía sociológica de los años difíciles 1935-1959, y es un testimonio inapreciable de una época difícil de entender (Pinilla 1996) ${ }^{6}$. Es el único testimonio de un sociólogo español que se conserva de esos años ${ }^{7}$.

La experiencia de la Guerra Civil produce una atención internacional sobre su desarrollo político y militar, pero mucho menos sobre sus causas y consecuencias sociales. Un libro imprescindible es The Spanish Labyrinth, del novelista y poeta británico Gerald Brenan, cuyo prefacio está fechado en diciembre de 1942. El libro se subtitula An Account of the Social and Political Background of the Civil War (Brenan 1943). Además del laberinto español, hay varias buenas historias de la guerra, desde la de Hugh Thomas (1976) o la de Pierre Vilar (1990) hasta un replanteamiento de autores esenciales en un libro editado por Edward Malefakis, La guerra de España 1936-1939, publicado recientemente -Malefakis (ed.), 1996-. Un estudio célebre es el de Gabriel Jackson, The Spanish Republic and the Civil War (1966) ${ }^{8}$. Hay dos trabajos extraordinariamente interesantes que plantean el tema de la memoria histórica de los/as españoles ante la guerra que, como bien señala Brenan, "arruinó España durante medio siglo». El primero es una investigación titulada Recuérdalo tú y recuérdalo a otros: Historia oral de la Guerra Civil española (Fraser 1979, 1996); el segundo, casi dos décadas después, es el trabajo de Paloma Aguilar Fernández sobre Memoria y olvido de la Guerra Civil española (1996).

Para entender el retraso en reaccionar del pensamiento sociológico tras la guerra es aconsejable analizar las hipótesis fundamentales escritas en La memoria inquieta (Pinilla 1996), especialmente sobre la responsabilidad diferencial de las clases sociales en -y después de- la contienda. La hipótesis del sociólogo Esteban Pinilla de las Heras sobre la burguesía catalana y española es central para entender ese período. Es importante también comprender las dificultades de elaborar, y sobre todo escribir, análisis de la realidad social en esos años. En forma de historias de vida, ese tema es analizado muy bien por Juan F. Marsal en dos libros clave, Pensar bajo el franquismo (1979) y La sombra del poder (1975). [Pancho] Marsal presenta numerosas ideas que generaciones posteriores de sociólogos/as conviene que estudien y desarrollen?.

${ }^{6}$ Las citas extactas puede verse en la bibliografía selectiva (un millar de libros) en Jesús M. DE Miguel, Estructura y cambio social en España (Madrid: Alianza Editorial, 1998), pp. 601653. La bibliografía en esas páginas está dividida en dos secciones: los estudios sociológicos globales, y las monografías sobre cambio social, desarrollo y procesos de desigualdad social. Aparecen por orden cronológico en la primera sección, y por orden alfabético en la segunda.

7 Véase también su libro En menos de la libertad (Pinilla de las Heras 1989). A nivel más literario, pero igualmente interesante, es el excelente diario de Zenobia Camprubí (sobre ella y la vida con su esposo, Juan Ramón Jiménez) en el exilio, desde 1937 hasta 1951 (Camprubí 1993, 1995). Es necesaria una lectura paciente y detallada.

${ }^{8}$ A partir de los años ochenta, Gabriel Jackson decide vivir en España y realiza una labor literaria importante, además de ensayista y de articulista en El País.

9 Juan Francisco Marsal Agelet muere accidentalmente el 5 de marzo de 1979. 
Es importante consultar algunas de las historias de la sociología española, que ofrecen una visión global de los progresos realizados, en particular en el estudio de la sociedad española. Hay tres que son importantes. El primer análisis serio de la sociología española se publica en inglés, en el año 1958, en un libro titulado The Recent Trends in Sociology. En ese libro, el capítulo sobre España está escrito por Enrique Goméz Arboleya (catedrático de Sociología en la Universidad de Madrid) y se titula "Sociology in Spain» ${ }^{10}$. Es el primer repaso moderno a la producción sociológica investigadora en España. Dos décadas después se publica en Londres y Los Ángeles el libro en inglés Sociology in Spain, que ofrece ya un estudio detallado por épocas, escuelas e instituciones, incluyendo una bibliografía clasificada por temas (J. M. de Miguel, y Moyer 1979) ${ }^{11}$. Otras dos décadas después aparece una reinterpretación de la historia de la sociología española centrándose en la investigación cualitativa, que es la sociología que menos atención atrae en las décadas anteriores. El libro, titulado Metodología cualitativa en España, está escrito por Bernabé Sarabia y Juan Zarco (1997).

Para tener una idea global de la producción sociológica española en el análisis de la realidad social es importante consultar alguna recopilación básica de trabajos o artículos. Hay tres especialmente interesantes. La primera es Sociología española de los años setenta (CECA 1971), que recoge en un grueso volumen algunos de los mejores artículos hasta esa fecha, incluyendo el artículo seminal de Enrique Gómez Arboleya sobre la sociología en España. Incluye, además, una bibliografía de los orígenes de la sociología española hasta 1956, así como un "quién es quién» de la sociología hasta el año 1970 realizado por Jesús M. de Miguel. La segunda es una recopilación de los artículos publicados por el Instituto de la Opinión Pública y (al cambiar de nombre) por el Centro de Investigaciones Sociológicas, titulada Veinticinco años de sociología en España (IOP/CIS 1988), en tres volúmenes. A partir de 1996 el CIS publica una English Edition anual de su Revista Española de Investigaciones Sociológicas (1996, 1997, 1998). Tiene la ventaja de ser una selección de los mejores artículos de la REIS — que es la revista no-oficial (aunque dependa del sector público) de la sociología española- y de presentarlos, además, a una audiencia internacional.

La Guerra Civil española es magnética y, a nivel internacional, atrae la atención de numerosos historiadores, novelistas (como George Orwell), poetas y fotógrafos (como Robert Capa). A partir de los años cuarenta, y a pesar de la dictadura de Franco, España se convierte en un laboratorio ideal para antropólogos/as que desean realizar su trabajo de campo sobre un país europeo peculiar. En la mayoría de los casos sus libros se publican en el extranjero, pero tienen un impacto intelectual considerable sobre los/as sociólogos autóctonos. El

${ }^{10}$ En español se publica luego en Gómez Arboleya (1959) y se reedita en Sociología española de los años setenta (CECA 1971). La Universidad de Madrid, o Universidad Central, es lo que ahora corresponde a la Universidad Complutense de Madrid.

${ }^{11}$ Para un contenido más biográfico es importante leer el excelente estudio de Amando de Miguel, Homo sociologicus hispanicus: Para entender a los sociólogos españoles (1973). 
análisis de la estructura social española, realizado desde dentro, está influenciado por algunos de esos estudios; así como la primera visión de la Guerra Civil fue transformada por The Spanish Labyrinth. La lista de esos estudios antropológicos y sociales es larga, pero conviene consultar al menos los siguientes:

1943 Gerald Brenan, The Spanish Labyrinth.

1950 Gerald Brenan, The Face of Spain.

1954 Julian A. Pitt-Rivers, The People of the Sierra.

1954 V. S. Prichett, The Spanish Temper.

1957 Gerald Brenan, South From Granada.

1962 Michael Kenny, A Spanish Tapestry: Town and Country in Castile.

1963 Julian A. Pitt-Rivers, Mediterranean Countrymen.

1969 William A. Douglass, Death in Murelaga.

1970 Dennison Nash, A Community in Limbo.

1971 Joseph Aceves, Social Change in a Spanish Village.

1972 William A. Christian, Person and God in a Spanish Valley.

1973 Patricia W. Fagan, Exiles and Citizens: Spanish Republicans in Mexico.

1975 Stanley Brandes, Migration, Kinship, and Community: Tradition and Transition in a Spanish Village.

1976 Davydd Greenwood, Unrewarding Wealth: The Commercialization and Collapse of Agriculture in a Spanish Basque Town.

1978 David D. Gregory, La odisea andaluza: Una emigración hacia Europa.

1979 Susan Tax Freeman, The Pasiegos: Spaniards in No Man's Land.

1980 Stanley Brandes, Metaphors of Masculinity: Sex and Status in Andalusian Folklore.

1980 David D. Gilmore, The People of the Plain: Class and Community in Lower Andalusia.

1986 Gary W. McDonogh, Good Families of Barcelona.

1990 Renate Lellep Fernandez, A Simple Matter of Salt: An Etnography of Nutritional Deficiency in Spain

1996 William A. Christian, Visionaries: The Spanish Republic and the Reign of Christ.

A la lista habría que añadirle algunos (pocos) estudios publicados en el extranjero realizados por españoles, como el famoso Belmonte de los Caballeros: Sociological Study of a Spanish Town (Lisón Tolosana 1966). Una coetánea interesante para entender el papel de estos/as analistas, y sus ideas, es la que edita María Cátedra con el título Los españoles vistos por los antropólogos (1991). Un 
interés complementario es el del exilio republicano de 1939 , en Francia o México. Produce estudios en el extranjero tan tempranos como el de Carlos Martínez (1959), y que continúan luego en Patricia W. Fagan (1973) y en estudios más recientes como el de Francisco Caudet (1997).

¿Hay investigación sociológica escrita dentro de España en los años cuarenta? Muy poca, es casi nula. Lo primero que germina son estudios demográficos, asépticos, con datos básicos e interpretaciones en concordancia con las ideas imperiales del franquismo y del nacionalcatolicismo. Un primer estudio es el de Jesús Villar Salinas, en 1942, sobre las Repercusiones demográficas de la última guerra civil española ${ }^{12}$. En la misma línea está uno de los artículos seminales de la época que inicia un debate sociológico importante, el del descenso de la natalidad. Está escrito por José Ros Jimeno en 1944: "El decrecimiento de la natalidad y sus causas». Al año siguiente, Ros Jimeno publica un libro titulado Estudios demográficos. Lo más parecido a un estudio sociológico global, como los que luego se explican en detalle, son los Estudios económico-sociales de Severino Aznar, publicados por el Instituto de Estudios Políticos, institución que durante la dictadura franquista juega un papel ambiguo: por un lado, parte ideológica de la dictadura y, por otro, dinamizador de un pensamiento social de tinte católico (Aznar 1946) ${ }^{13}$.

La década termina con algún leve replanteamiento de las tesis orteguianas, y de la generación del 98, en el temprano libro de Pedro Laín Entralgo, España como problema (1949). Conviene comparar sus tesis de 1949 con las de dos décadas después en otro libro suyo titulado, significativamente, ¿A qué llamamos España? (1971). En esos años, sólo algunas revistas como Leonardo, Revista de las Ideas y las Formas o Laye muestran algún signo de modernidad. Sobresalen los artículos de Esteban Pinilla de las Heras (a menudo bajo el seudónimo de Steparius), que demuestra su valor como sociólogo crítico en unos años de dura represión intelectual (Pinilla de las Heras 1946, 1950-1954). Los años cuarenta son de sequía sociológica, y cualquier estudio sobre la estructura social que se pretenda realizar sobre esa década apenas puede apoyarse en estudios de la época. Los años del hombre terminan con el estudio fotográfico de W. Eugene Smithm, The Spanish Village, realizado en 1950 en el pueblo de Deleitosa, en Extremadura (Cáceres). Es el reportaje fotográfico y periodístico más impresionante sobre esa "España negra». La obra de Smith se recupera medio siglo después (MNAC 1999), de ser publicada en Life (9 abril 1951).

${ }^{12}$ Es interesante aquí la utilización de la expresión «última». Una década después, el mismo autor seguía publicando estudios demográficos avalorativos como Tendencia contemporánea de la mortalidad infantil española (Villar 1951).

${ }^{13}$ En 1942, F. Javier Conde publica Contribución a la doctrina del caudillaje. 


\section{LA AUTARQUÍA}

La década de los cincuenta se caracteriza en España por una natalidad contenida, como consecuencia de la pobreza y la opresión social que significan los primeros lustros de la dictadura de Franco. El baby boom se retrasa significativamente hasta los años sesenta. La labor de los sociólogos antifranquistas y demócratas en el interior de España es clandestina, como puede verse en el "Manifiesto de las generaciones ajenas a la Guerra Civil», escrito y difundido en 1955-1956 por Esteban Pinilla de las Heras. Es, sin embargo, un caso extraordinario $^{14}$. Sólo hacia el final de la década de los cincuenta se publican algunos estudios importantes para entender la sociedad, con visiones históricas un poco más «sociales» como la de Vicens Vives (1954, 1957). Tienen importancia como dinamizadores de una nueva generación de sociólogos/as dentro del país. Siguen siendo populares los estudios demográficos, que al parecer no ofrecen riesgo para el régimen político, y que incluso están en la onda imperial de los discursos de Franco relativos a la polémica de los cuarenta millones de españoles. Aparecen también estudios sobre la familia española, a favor de sus supuestas virtudes peculiares.

Una cierta brisa nueva se inicia con un investigador maduro, Román Perpiñá, mezcla curiosa de economista, humanista, y protosociólogo. En 1952 publica De estructura económica y economía hispana, y a partir de 1954 desarrolla su teoría de la Corología. Ese libro clave se subtitula Teoría estructural y estructurante de la población de España 1900-1950 (R. Perpiñá 1954), que desarrolla luego en trabajos posteriores $(1962,1964,1972)^{15}$. Es todavía un libro sobre demografía, población y urbanismo, pero está lleno de ideas novedosas. Las dictaduras permiten a veces este tipo de estudios, ingeniosos, siempre que no cuestionen temas sustanciales.

Hasta mediados de la década de los cincuenta, España permanece aislada del mundo. Eso no impide que algunos sociólogos inteligentes se planteen el análisis de la sociedad y de la desigualdad social, como Esteban Pinilla de las Heras en su artículo «Sobre ciertos problemas que plantea la noción de estructura social» (1956). A la mitad de la década, con los primeros tratados internacionales con Estados Unidos y el Vaticano, España se abre un poco. Se llevan a cabo las llamadas Semanas Sociales en España, que analizan temas como Los problemas de la emigración española (Junta Nacional 1958). Luego, en 1959, el Instituto Balmes de Sociología edita en cuatro volúmenes sus Estudios demográficos, que con más de dos mil páginas representan el testamento de esa institución durante la primera parte del franquismo. Resume, además, la aportación de la sociología oficial dentro del Consejo Superior de Investigaciones 1989).

14 Aparece publicado finalmente en su libro En menos de la libertad (Pinilla de las Heras

15 No conviene confundir a este Román Perpiñá Grau con Antonio Perpiñá Rodríguez, ideológica y científicamente diferenciados. 
Científicas ${ }^{16}$. Supone una especie de estudio global de la sociedad española, centrada — como sugiere su título- en el análisis de la población. Además de la demografía, preocupan el sector rural y la familia.

Los organismos internacionales colaboran en los aspectos del desarrollo que presentan un atraso más claro. Así, la FAO en 1959 publica su Proyecto de desarrollo de la región mediterránea. Aparecen a partir de entonces, tímidamente, algunos estudios que tienen una importancia dinamizadora, todos en el mismo año. Francisco Murillo Ferrol —quien luego tiene una importancia considerable en el desarrollo de la sociología y la ciencia política en Españapublica en Granada Las clases medias en España (1959), ya con un estilo diferente. Igualmente, Miguel Siguán escribe en Barcelona Del campo al suburbio (1959). Se observa que la innovación se desarrolla en la periferia, ya que el centro (Madrid capital) está dominado por el franquismo ${ }^{17}$.

En el mismo año de 1959 se lleva a cabo en Madrid el Congreso de la Familia Española, organizado por Manuel Fraga Iribarne bajo control oficial. Sin embargo, entre sus ponencias aparecen algunos estudios empíricos más modernos. José Ros Jimeno sigue con la obsesión poblacionista del régimen franquista en La familia en el panorama demográfico español (1959). Enrique Gómez Arboleya (meses antes de suicidarse), junto con Salustiano del Campo, quien acaba de volver de estudiar sociología en Estados Unidos, publican Para una sociología de la familia española $(1959)^{18}$. Aparece significativamente con un prólogo de Manuel Fraga Iribarne. Este último edita varios libritos de las Ediciones del Congreso de la Familia Española, uno de ellos titulado La familia y la educación en una sociedad de masas y máquinas (Fraga et al. 1960). La ideología de estas publicaciones «familiares» está dentro de la ortodoxia franquista, pero plantean temas relativamente más modernos y sociológicos.

Es precisamente a finales de esta década de los cincuenta cuando se llevan a cabo en España las tres primeras encuestas modernas: sobre juventud, profesión médica, y empresarios. La de juventud — «Encuesta de Juventudes»— está patrocinada por el propio Gobierno, con un cuestionario a nivel nacional que se titula Presupuestos mentales de la juventud española 1960 (López Cepero et al. 1960). Esta encuesta, cuyo diseño es realizado por Juan J. Linz, abre una línea de estudios oficiales sobre la juventud, que continúan con la democracia impulsados por el Instituto de la Juventud (A. de Miguel 1966; Instituto de la Juventud 1968; Zárraga 1985, 1989; Martín Serrano 1991; Navarro y Mateo 1993; Martín Serrano y Valverde 1996). Del primer estudio de 1959, cuyos datos valdría la pena investigar en profundidad alguna vez, se publican estudios parciales.

${ }^{16}$ Años más tarde, la biblioteca del Instituto Balmes de Sociología se quema y es posible que estos libros hayan desaparecido. Sin embargo, mantienen un interés considerable y deberían ser analizados con detalle.

${ }_{17}$ Una excepción curiosa es el breve artículo de José Ros Jimeno, "Las clases sociales y el problema de su determinación», publicado en 1959.

${ }_{18}$ Los datos provienen de una pequeña muestra de 127 estudiantes en Madrid y 112 en Salamanca; con un cuestionario de 37 preguntas. 
La segunda encuesta es a la profesión médica, Encuesta sobre la profesionalidad médica en España, realizada por José Mariano López Cepero, Amando de Miguel, Luis González Seara, y José Castillo, también con el asesoramiento de Juan J. Linz. El estudio incluye una muestra de unos quinientos médicos/as, una muestra de élites y un panel de estudiantes de Medicina. Apenas fue concluida y se publica poco de la investigación. Aparece luego un estudio a una muestra de 125 médicos de Barcelona que se edita un lustro después: Problemas de la profesión médica española (Del Campo 1964).

La tercera encuesta, financiada por la Escuela de Organización Industrial (en Madrid), es muy importante en la sociología española. Analiza empresarios (con una muestra de 460). La encuesta da origen al libro conjunto Los empresarios ante el poder público (Linz y A. de Miguel 1966) y a una serie de excelentes artículos elaborados fundamentalmente en Estados Unidos (Columbia University y en el Center for Behavioral Studies de Palo Alto, en California) por Juan J. Linz y Amando de Miguel, dos de los sociólogos españoles más prolíficos e interesantes del siglo XX. Un estudio similar sobre el empresariado catalán - también excelente- aparece un par de años después realizado por Esteban Pinilla de las Heras: Los empresarios y el desarrollo capitalista: El caso catalán (1968). Las tres encuestas de 1959 representan el punto de arranque fundamental del análisis "empírico" de la realidad social española con nuevos métodos, importados en esa época fundamentalmente de Estados Unidos, Francia, y Gran Bretaña. Aunque las tres encuestas se llevan a cabo desde Madrid.

La década de los cincuenta es poco pródiga en investigaciones sociológicas, y sólo hacia el final realmente se empieza a investigar con metodología sociológica. Entre los jóvenes que se inician en esta época se mencionan los nombres de algunas de las personas más representativas del análisis de la estructura social española durante el resto del siglo. Van a aparecer luego dirigiendo investigaciones, estudios sociológicos globales, empresas de investigación y Departamentos universitarios: Salustiano del Campo, José Castillo, Luis González Seara, Juan J. Linz, Amando de Miguel, Francisco Murillo Ferrol y Esteban Pinilla de las Heras, entre otros; e incluso la polifacética figura de [don] Manuel Fraga Iribarne, dedicado luego más a la política que a la ciencia. En el interior de España no se produce al final de la década una revisión global de esa aciaga época. Es un latinoamericano, Carlos M. Rama, quien oportunamente publica en el extranjero - en México DF y Montevideo- su estudio sobre La crisis española del siglo XX (1960), y que años más tarde reelabora como Ideología, regiones y clases sociales en la España contemporánea (1963). Son dos aportaciones esenciales para entender la estructura social española.

\section{EL DESARROLLO}

Como se vislumbra ya desde su inicio, la década de los sesenta es de una productividad sociológica considerable en estudios sobre la sociedad española. 
Todo ello a pesar del franquismo, y quizás a causa del desarrollo económico. La década se inicia con estudios del mismo tipo que los avanzados en los años precedentes. En 1960, Salustiano del Campo publica un estudio sobre La familia española en transición, en que señala algunos de los cambios que se producen en la estructura familiar. El mismo año, y el mismo sociólogo, sigue con el tema de las clases medias (iniciado por Francisco Murillo) con el libro Las clases medias y la movilidad social en la sociedad industrial (del Campo 1960). Hay una prolongación de estudios de población, que es la tarea típica de la investigación oficial, en La morbilidad de la infancia en España 1901-1951 (Arbelo 1962).

Aparece pronto uno de los ensayos básicos para entender la estructura social y política española. Se publica en el exterior, en Buenos Aires: Escrito en España, de Dionisio Ridruejo (1962). Es un libro pensado desde la oposición, lleno de ideas distintas de las que se permite discutir en el interior del país, y que tiene una cierta influencia sobre los sociólogos/as de esa década y posteriores. Es prohibido por la dictadura. También desde el exilio en Latinoamérica, Francisco Ayala publica España, a la fecha (1965). Es interesante comparar sus ideas con las que dos décadas después presenta en Norteamérica en La imagen de España (Ayala 1986). Los dos autores - Ridruejo y Ayala - tratan de dar sentido a la posición de España en el mundo, y a la peculiar estructura social y política del país. Ambas interpretaciones provienen del campo de la literatura en frontera personal con la política y la sociología. Un caso excepcional son los artículos de Esteban Pinilla de las Heras sobre "Cambios estructurales en la sociedad española", publicados en 1965 en la revista Mañana: Tribuna Democrática de España con el seudónimo de Steparius. En el interior del país la interpretación es bastante más conservadora (no se podía publicar de otra manera), como queda patente, por ejemplo, en la reflexión de Julián Marías en su libro Los españoles (1962). Es importante analizar la forma en que ese autor va cambiando de ideas en Meditaciones sobre la sociedad española (Marías 1966) y, dos décadas después, en España inteligible: Razón histórica de las Españas (Marías 1985).

Mucho de lo que empieza a cambiar en España se produce por la influencia de organismos internacionales, y especialmente por el BIRF, la Unesco, y la OCDE. En 1962 aparecen dos de los informes más importantes. El primero, conocido como el «Informe del Banco Mundial» (Oficina de Coordinación y Programación Económica 1962), se publica como El desarrollo económico de España (BIRF 1962), al que le sigue unos años después un informe más detallado sobre el sector agrario, El desarrollo de la agricultura en España (BIRF 1966). El objetivo común es el desarrollo económico, planificado, sin cambiar el régimen político dictatorial. Preocupa especialmente el sector agrario, ya que entonces es la base de la economía, y aparece claramente retrasado respecto del resto de Europa. Un ejemplo de estudios sobre el sector rural de la época es el libro Estructura y problema del campo español (Anlló 1966). El sociólogo Víctor Pérez Díaz inicia su producción investigadora con temas sociológicos agrarios: 
Estructura social del campo y éxodo rural (1966) y, años después, Pueblos y clases sociales en el campo español (1974, 1992).

La otra influencia importante proviene del conocido «Proyecto Regional Mediterráneo», sobre las necesidades de educación para lograr el desarrollo económico-social de España (Ministerio de Educación Nacional y OCDE 1963). Viene introducido unos meses antes por un estudio sobre La educación y el desarrollo económico-social: Planteamiento integral de la educación. Objetivos de España para 1970, del Ministerio de Educación Nacional (español) y la Unesco (1962). Se tarda toda la década de los sesenta en lograr ese cambio del sector educativo, que cristaliza en el llamado Libro Blanco, que corresponde al informe La educación en España: Bases para una politica educativa (MEC 1969). Da origen al año siguiente a la Ley General de Educación, que es la primera reforma educativa en España después de ciento trece años ${ }^{19}$. Supone una serie de revisiones directas por parte de la profesión sociológica, con una crítica implícita a la estructura política del país durante los años sesenta. Un ejemplo de ese análisis es el libro El capital humano (Romero y A. de Miguel 1969).

El Informe del Banco Mundial y el Proyecto Regional Mediterráneo preparan el Primer Plan de Desarrollo Económico y Social, que abarca los años 1964-1967. La ponencia de Factores humanos y sociales del Plan tiene interés sociológico (Comisión del Plan de Desarrollo Económico y Social 1963). Se señalan grandes problemas de pobreza y de subdesarrollo en el país, de educación, retraso en la agricultura, etc. Pero la sociedad española está ya cambiando, experimentando un incremento sensible de la fecundidad y una alta tasa de movilidad geográfica.

La Iglesia Católica española se transforma lentamente. Algunos sectores eclesiales tratan de aplicar el nuevo conocimiento científico y sociológico a un plan que se denomina "Comunicación Cristiana de Bienes» (CCB) y que plantea la preocupación por atender a algunas de las regiones más pobres dentro de España como una forma de nivelar las desigualdades sociales. La investigación cubre toda la década pues se realiza entre 1961 y 1964, y se publica entre 1965 y 1968. Produce un informe monumental, que es el primero de la serie de grandes estudios sociológicos globales sobre la situación social española. Se titula Plan CCB: Plan de promoción social, asistencia social y beneficencia de la Iglesia en España (Cáritas Española 1965-1968) ${ }^{20}$. No es un informe dirigido a la Iglesia Católica, ni tampoco al Gobierno (franquista), sino a la población y a los grupos con poder dentro de la sociedad. La misma fórmula se aplica a otros estudios sociológicos globales, que analizan la estructura de la sociedad, los cambios sociales y los problemas sociales más importantes. Ofrecen sus datos e interpretaciones a la población.

Los estudios sociológicos globales — que hay dos en esta década — se anali-

19 Hay otro Libro Blanco sobre la educación veinte años después, pero entonces con un Gobierno socialista y con un sociólogo como ministro de Educación (MEC 1989).

${ }^{20}$ Se refiere a la Iglesia Católica. 
zan con más detalle en el siguiente epígrafe. El tema de la pobreza es central en el Plan CCB y una preocupación constante en la década de los sesenta. Un estudio más testimonial de esta época es el libro Els altres catalans (Candel 1964). Demetrio Casado es el investigador que tiene un impacto mayor en el tema de la pobreza tras la Guerra Civil, con estudios como Perfiles del hambre (1967), que luego continúa en La pobreza en la estructura social de España (1971) y, dos décadas después, replantea en Sobre la pobreza en España 19651990 (1990).

El éxito del Plan CCB da origen al inicio de la serie más importante de estudios sociológicos globales que existen en España sobre la estructura social y los procesos de cambio de la sociedad: los cinco Informes de la Fundación Foessa. El primer Informe se publica en 1966, y supone la primera contribución al análisis global de la sociedad española y la más importante en la historia de España hasta finales de la década de los sesenta. Supone, además, una perspectiva científica, empírica, relativamente progresiva, aunque sin cuestionar la dictadura franquista. Hay que entender que en esos años la producción sociológica interior sufre un importante control político y censura previa. Los temas sociológicos oficiales son debatidos en el Centro de Estudios Sociales de la Santa Cruz del Valle de los Caídos ${ }^{21}$. Las reuniones se realizan por invitación, pero no pueden evitar que sociólogos jóvenes empiecen a debatir ideas novedosas y algo críticas. La lista de algunos de los estudios más sociológicos del Centro de Estudios Sociales da una idea de la importancia que se da entonces a los cambios sociales y morales que acompañan al desarrollo económico:

\section{Problemas sociales y morales de los movimientos de población en España. \\ 1967 La familia española. \\ 1967 El progreso económico y el orden social. \\ 1968 Sociología de la Administración Pública española. \\ 1969 La concentración urbana en España. \\ 1970 La educación en España. \\ 1971 La sociedad del año 2000. \\ 1974 Desarrollo y justicia social.}

Todos estos volúmenes son importantes y, junto a ideologías franquistas, suponen a veces avances modernizantes. Pero nunca se analiza seriamente -y menos aún se trata de cambiar- el régimen político. El objetivo es más bien solucionar los problemas que se producen por la relativa liberalización social y los planes de desarrollo que se ponen en marcha a partir de 1964.

En las mismas fechas la producción sociológica sobre España en el extranjero es mucho más moderna y crítica. Uno de los españoles que más contribuyen al análisis de la estructura social y política de España es Juan J. Linz (pri-

${ }^{21}$ El monasterio construido por Franco, y en donde están enterrados actualmente Francisco Franco y José Antonio Primo de Rivera. 
mero en Columbia University y luego en Yale University). Su autobiografía parcial es importante para entender las dificultades de una formación académica seria en ciencias sociales dentro de España durante el franquismo ${ }^{22}$. Es interesante contrastar algunos de sus estudios de esa época con los que se estaban produciendo en el interior de España. La lista empieza con su "An authoritarian regime: Spain» (Linz 1964), que es uno de los artículos más importantes y debatidos en España, y que mantiene todavía una singular influencia en el mundo ${ }^{23}$ :

1964 «An authoritarian regime: Spain».

1966 "Whithin-nations differences and comparisons: The eight Spains».

1967 "The party system of Spain: Past and future».

1970 «From Falange to Movimiento-Organización: The Spanish single party and the Franco regime, 1936-1968».

1972 «Five centuries of Spanish history: Quantification and comparison».

1972 "Opposition in and under an authoritarian regime: The case of Spain».

1973 «Early state-building and late peripheral nationalisms against the state: The case of Spain».

1975 «Politics in a multilingual society with a dominant world language: The case of Spain».

1975 «Totalitarian and authoritarian regimes».

«El régimen autoritario» o "Las ocho Españas», como se conoce a los dos primeros trabajos, suponen un cambio de rumbo en la investigación sociológica en el interior del país ${ }^{24}$. Esta selección de nueve artículos representa bien el nivel de reflexión que se introduce en España, a través de las publicaciones en inglés, al menos entre un grupo de intelectuales preocupados seriamente con el futuro político, además de con la estructura social de España. Coloquialmente, la serie completa se conoce como The Case of Spain. El impacto intelectual de Juan J. Linz en la ciencia social española es extraordinariamente importante. Es seguramente la persona que mayor influencia tiene en la sociología española durante el siglo XX.

${ }^{22}$ Es una excelente entrevista realizada por su esposa, Rocío Terán (Linz 1994). Debería ser lectura obligatoria para cualquier estudiante con vocación sociológica en España. La de Linz es verdaderamente una historia ejemplar. La sociología (y ciencia política) española debe muchísimo a Juan J. Linz, a su sabiduría, y a su legendaria generosidad intelectual.

${ }^{23}$ Una muestra de las incongruencias del régimen es que en 1969 el artículo es publicado en español por el propio Ministerio de Trabajo franquista. Linz ya había publicado antes de 1964 varios trabajos sobre España, pero este artículo es decisivo para el análisis del régimen franquista y los cambios sociales.

${ }^{24}$ El tema de tipos de regímenes lo desarrolla teóricamente en Juan J. LinZ, «Totalitarian and authoritarian regimes», en Fred I. Greenstein y Nelson W. Polsby (eds.), Handbook of Political Science (Reading, Mass.: Addison Wesley, 1975), vol. 3: «Macropolitical Theory», pp. 175-411. 
Algunos autores extranjeros se dedican en esta década a realizar estudios sobre España, como la excelente historia Spain 1808-1939, de Raymond Carr (1966). También está el libro Politics and the Military in Modern Spain, de Stanley G. Payne, en 1967 (en español publicado por Ruedo Ibérico en París en 1968). En Barcelona, Julio Busquets publica uno de los primeros estudios sobre militares, El militar de carrera en España (1967), que sufre censuras y cortapisas a pesar de que no cuestiona el régimen franquista. Estos condicionantes explican que la mayor parte de la producción científica se siga realizando desde el exterior.

Ruedo Ibérico es una editorial especializada en temas sobre España, en París, y que publica en español. Realiza una coetánea o estudio sociológico global que denomina Horizonte español. Se publican al menos dos; en 1966 con dos volúmenes y en 1972 con tres volúmenes. En la edición de 1966 es interesante consultar el artículo de Esteban Pinilla de las Heras sobre «España: Una sociedad de diacronías». La misma editorial publica La estabilidad del latifundio, de Juan Martínez Alier (1968), un estudio básico para entender la estructura agraria del Sur. A mediados de los sesenta se nota en el exterior de España un interés por analizar la estructura social y no sólo la historia o la política en España. El Sur, Andalucía, atrae la atención por múltiples razones: la pobreza, una alta natalidad, estructura rural pero con agrociudades, y un sistema de clases desigual. Además, Andalucía sigue expresando la españolidad más tópica, de la que se aprovecha el franquismo. Se inician estudios más profundos como Factores de la estructura socio-económica de Andalucía Oriental (Cazorla 1965) o La España del Sur (Comín 1965).

En la segunda parte de los años sesenta hay también una eclosión de intereses diversos sobre la estructura de la sociedad española dentro del país. Los estudios más generales plantean el cambio de una sociedad tradicional a otra más moderna. Julio Caro Baroja — una peculiar mezcla de antropólogo, sociólogo, humanista- escribe Estudios sobre la vida tradicional española (1968) y El mito del carácter nacional (1970). Lógicamente, la investigación social refleja los cambios sociales que se producen. Se inician estudios sobre movilidad social, como el importante artículo "Social and geographical mobility in Spain» (A. de Miguel 1965). Hay otros estudios sobre migraciones interiores, un tema que es importante dado el volumen de personas que en pocos años cambian de municipio de residencia en esos años (García Barbancho 1967, 1975).

La investigación sobre sociología de la religión sigue siendo poco crítica, pero empiezan ya a aparecer algunas obras peculiares. Un estudio clave es el artículo de dos jóvenes sociólogos —Luis González Seara, quien luego es ministro de Educación, y Juan Díez Nicolás, luego rector, director general y subsecretario- publicado en 1966 sobre "Progresismo y conservadurismo en el catolicismo español». En el mismo año, Rogelio Duocastella publica Análisis sociológico del catolicismo español. Poco después aparece un libro sobre Los protestantes españoles (Estruch 1968) y, al año siguiente, una de las reflexiones filosóficas que más impacto tienen en la época, La crisis del catolicismo, de José L. López Aranguren (1969). 
Pero el tema que más estudios concentra es la evolución de España hacia una "sociedad de consumo de masas», en la expresión que se utiliza en esos años. Hay una mezcla de optimismo y miedo a ese modelo de sociedad; y cuyo recelo es difundido ideológicamente por el régimen franquista, temeroso de los cambios que se están produciendo a nivel social. La polémica la inicia, en 1968, José Castillo con su libro La sociedad de consumo. En el mismo año, Data SA (empresa estrechamente vinculada a Juan J. Linz y Amando de Miguel) publica un estudio de encuesta sobre los Comportamientos y actitudes de las economías domésticas hacia el ahorro y el consumo. Aparece luego el libro España, ¿una sociedad de consumo? (A. Míguez 1969). José Castillo replantea la discusión con un artículo importante: «Las clases medias: ¿Mito o realidad?» (1969). Toda la discusión se explica mejor al cabo de unos años en Sociedad de consumo a la española (J. Castillo 1987).

Aparecen al final de la década de los sesenta otros estudios de sociólogos que representan ya intereses nuevos, y que abren líneas diferentes de investigación. En 1967, José M. Maravall —entonces un joven investigador, luego profesor en la Universidad de Warwick (en Gran Bretaña) y que posteriormente llega a ministro de Educación (en España) — publica Trabajo y conflicto social en Edicusa. Esta editorial, desde su orígenes cristianos, se compromete con estudios moderadamente críticos de la situación social. Al año siguiente, Luis González Seara (luego ministro de Educación) reúne varios de sus artículos más sociológicos en Opinión pública y comunicación de masas (1968). Uno de los estudios sociológicos más innovadores de la época es Hacer la América, de Juan F. Marsal (1969), realizado por su autor entre Estados Unidos y Argentina. Es uno de los mejores ejemplos de historias de vida. Es un estudio que tiene un impacto considerable sobre un grupo de sociólogos españoles ${ }^{25}$. Sigue siendo un trabajo excelente de consulta obligada.

\section{TRANSICIÓN POLÍTICA}

La década de los setenta supone el desarrollo de estudios sobre el paso desde el "tardofranquismo» (los últimos años del régimen de Franco, que finaliza en noviembre de 1975) y la transición a la democracia, que termina usualmente con la resolución del golpe de Estado de febrero de 1981. Antes de la muerte de Franco se nota ya una actitud bastante más crítica en los estudios sociológicos, que enfocan directamente el análisis de la estructura social, aunque apenas se analiza todavía el régimen político. Una excepción es el artículo de Antonio López Pina sobre "Desarrollo y política en España», publicado en 1971. La caída del régimen - por muerte natural del dictador- lleva a una reflexión inmediata. Pero es preciso esperar unos años más para que se publiquen estudios más profundos.

25 Otro estudio importante se publica unos años después, Testimonio de un rebelde (Maestre 1976). 
La década de los setenta comienza con estudios importantes sobre obreros y jornaleros. Así, aparece en español Reforma agraria y revolución campesina en la España del siglo XX, de Edward Malefakis (1970). Siguen otros estudios sobre la estructura del campo español (J. M. de Miguel 1970). Juan J. Linz publica uno de los estudios empíricos más interesantes de la época, Élites locales y cambio social en la Andalucia rural (1971). Años después se edita en el exterior The Changing Faces of Rural Spain (Aceves, y Douglass eds. 1976). Por su parte, José M. Maravall analiza los/as trabajadores en El desarrollo económico y la clase obrera (1970).

Con problemas de censura aparece el segundo Informe Foessa (1970), que se convierte en el mejor de los estudios sociológicos globales y, sin duda, el estudio sociológico sobre la estructura social española más avanzado para la época. Tenía que incluir un capítulo sobre "Vida política y asociativa" —el famoso Capitulo 5-, pero la censura franquista lo arranca literalmente del voluminoso informe, sin ni siquiera repaginar. Las páginas 371 a 431 (con sus 54 tablas) desaparecen del libro, aunque inmediatamente ediciones pirata de ese capítulo se difunden ampliamente entre profesores e investigadores. El informe aparece luego (sin el capítulo de política) en forma de síntesis que se utiliza como libro sociológico de bolsillo (A. de Miguel 1972). Este hecho muestra el rechazo frontal del régimen a toda crítica, incluso en sus años finales. La dictadura de Franco nunca permite el análisis sociológico de la estructura política del régimen ${ }^{26}$.

Es la editorial Ruedo Ibérico, en París — publicando en español—, la que lidera la producción de estudios críticos sobre/contra el franquismo y los grupos en el poder. Entre los títulos están La prodigiosa aventura del Opus Dei (Ynfante 1970), El Opus Dei en España 1928-1962 (Artigues 1971), Horizonte español 1972 (1972), Franco frente al Rey (Calvo Serer 1972) y El Ejército de Franco y de Juan Carlos (1976). Está por escribir un estudio sobre la contribución de las editoriales extranjeras (en español o en otros idiomas) a la comprensión de la situación española en el tardofranquismo y luego en la transición democrática.

La antigua manía de estudios demográficos de la postguerra es sustituida por investigaciones más modernas. Juan Díez Nicolás, sociólogo formado en la Universidad de Michigan, publica Tamaño, densidad y crecimiento de la población en España (1971), complementándolo en sus aspectos más urbanos con el estudio Especialización funcional y dominación en la España urbana (1972). El interés por las diferencias regionales se plasma en estudios importantes como el de Amando de Miguel y Juan Salcedo sobre Dinámica del desarrollo industrial de las regiones españolas (1972). Salustiano del Campo presenta también en esas fechas una serie de estudios demográficos, empezando con el Análisis de la población de España (1972), que amplía en La política demográfica en España (1974). Muchas de las ideas suyas de esos años son repensadas años más tarde

${ }^{26}$ Si alguien desea una copia del Capitulo 5 puede solicitármela. Gustosamente enviaré una fotocopia. 
en su libro Nuevo análisis de la población española (del Campo y Navarro 1987). Se siguen realizando estudios demográficos pero con enfoques más novedosos, como El ritmo de la vida social (J. M. de Miguel 1973), que incluye un estudio del suicidio. Otros sociólogos se interesan por temas urbanos, que supone una nueva especialidad sociológica dentro del país. Uno de los investigadores más imaginativos es Mario Gaviria, con Campo, urbe y espacio del ocio (1971, 1974), que luego complementa con temas de medio ambiente en Ecologismo y ordenación del territorio en España (1976).

Aparecen, por fin, algunos de los primeros estudios plenamente sociológicos sobre la condición de la mujer. María Ángeles Durán publica en 1972 un primer estudio sobre El trabajo de la mujer en España. Es el inicio de una serie de estudios de esta socióloga, que se van espaciando en el tiempo, todos ellos de enorme interés: Dominación, sexo y cambio social (1977), Liberación y utopia (1982), La jornada interminable (1987) y De puertas adentro (1988). Tienen un impacto considerable en el estudio del género, que la sociología española durante lustros apenas desarrolla. El tema del divorcio se analiza al final de la década en Historia y sociología del divorcio en España (I. Alberdi 1979).

Justo antes del final del franquismo se observa un renovado interés por estudios de estratificación, estructura social, y desigualdades sociales. En todos ellos se trata de relacionar la política con la economía, y ambas con la sociedad. Es una fórmula que se repite a menudo en España. Se publica uno de esos estudios tripartitos, La España de los años setenta, en tres volúmenes (Fraga, Velarde, Del Campo, 1972). Los temas de estratificación social pueden verse en estudios sociológicos serios como Estratificación social y movilidad social en España en la década de los setenta (Díez Nicolás y Del Pino, 1972), en Estratificación social en España (Cazorla 1973) y su continuación en Problemas de estratificación social en España (Cazorla 1977). La empresa Data SA de investigación sociológica, en Madrid, edita la Estructura social básica de la población de España y sus provincias (1973). Aparecen estudios más críticos, con perspectivas marxistas, como el de Clases sociales en España en el umbral de los años setenta (Fernández de Castro y Goytre 1974). Pero, sin duda, el estudio más denso y documentado es el excelente Manual de estructura social de España, de Amando de Miguel (1974). Es en realidad un manual inacabado pues faltan sectores esenciales; el segundo volumen nunca ve la luz. La muerte de Franco en noviembre de 1975 trastoca muchas cosas en España.

$\mathrm{Al}$ inicio de ese año 1975 se nota que algo está cambiando. El sociólogo Luis González Seara, con buen olfato político, lo desarrolla en su libro Espa$\tilde{n} a$, en el umbral del cambio (1975). Es interesante comparar ese libro suyo con el de una docena de años después, La década del cambio (González Seara 1987). También se notan transformaciones en la Iglesia Católica, que son analizadas ese mismo año en Catolicismo nacional: Nostalgia y crisis (González Anleo 1975). El tema clave es entonces el del poder, pero con una visión sociológica que hasta esos años apenas se permite. Innovador, como en muchas otras cosas, Juan F. Marsal publica en 1975 un excelente análisis, 
La sombra del poder: Intelectuales y política en España, Argentina y México. Colaborando con él (y con Amando de Miguel), Benjamín Oltra escribe Pensar en Madrid: Análisis sociológico de los intelectuales políticos en la España franquista (1975). Marsal redondearía luego el estudio de los intelectuales durante el franquismo con un libro importante, Pensar bajo el franquismo: Intelectuales y politica en la generación de los años cincuenta (1979). La década de los cincuenta permanece en casi total oscuridad para la sociología, y aun actualmente el conocimiento es pequeño.

Hacia el final del franquismo, varios sociólogos españoles — dentro de España- se dedican a analizar el poder y la estructura de clases. Carlos Moya publica El poder económico en España 1939-1970 (1975). La estructura de clases tiene en José Félix Tezanos un estudioso que renueva las ideas y los temas en Las nuevas clases medias (1973), un estudio de empleados/as de banca, y, sobre todo, en Estructura de clases en la España actual (1975). Tras el franquismo completa la investigación con Estructura de clases y conflictos de poder en la España postfranquista (1978). El poder judicial es también analizado por la pluma de uno de los mejores sociólogos jóvenes, formado en Yale University con Juan J. Linz: José Juan Toharia, quien publica Cambio social y vida jurídica en España (1974) e inmediatamente después uno de los estudios sociológicos de profesiones más interesantes de esos años: El juez español (1975). Toharia continúa con su interés por los estudios judiciales en la siguiente década combinándolo con otros temas. Es importante ¡Pleitos tengas...! Introducción a la cultura legal española (Toharia 1987) y Los españoles ante la Administración de Justicia (Toharia 1988).

Franco muere de muerte natural. En el mismo año muere Dionisio Ridruejo, poco antes escribiendo esos versos de "Español apagado, ceniza de un fuego, ¿dónde estás que te busco, y me busco y nos pierdo?» ${ }^{27}$. La muerte del dictador sorprende a todos los/as sociólogos, a pesar de que ya se llevaba tiempo realizando encuestas de opinión y de valores a la población española. Entre los estudios importantes en esa fecha crítica está Los españoles de los años setenta (López Pintor y Buceta 1975). La larga agonía de Franco sucede mientras el tercer Informe Foessa está en imprenta. A última hora hay que incluir un prefacio y un epílogo al Informe que salven el momento difícil en que va a salir a la calle ${ }^{28}$. Hay que tener en cuenta que aunque se publica en 1976 la encuesta corresponde a 1973 y, por lo tanto, es un informe todavía de la época franquista, con censura y autocensura. Pero su publicación se realiza, e incluso se edita una síntesis del mismo (Casal et al. 1978), sin problemas.

Algunos sociólogos/as sacan inmediatamente a la luz estudios sobre Franco y la figura de Franco. Uno de los textos más influyentes de la época, que se convirtió en un best-seller, es La sociología del franquismo: Análisis ideológico de

${ }^{27}$ Dionisio Ridruejo, En breve (1975).

${ }^{28}$ El prólogo es de Luis González Seara, «Los nuevos españoles», y el epílogo de Enrique Martín, "Aspectos sociales y políticos del desarrollo económico español». Sus ideas son opuestas. 
los ministros del régimen, de Amando de Miguel (1975), con numerosas ediciones. El mismo autor continúa la disección sociológica de la figura de Franco en otros libros como La herencia del franquismo (1976) y Franco, Franco, Franco (1976). Sirven para desmitificar al dictador y demostrar que el análisis de la realidad política y social es posible e importante. En esos años, Amando de Miguel publica además varios libros sociológicos sobre España: Cuarenta millones de españoles cuarenta años después (1976), Reformar la universidad (1976), Recursos humanos, clases y regiones en España (1977), y La pirámide social española (1977).

Otros/as sociólogos y politicólogos colaboran en esa respuesta inmediata investigadora sobre el franquismo. Antonio López Pina, con Eduardo López Aranguren, publica La cultura política de la España de Franco (1976) y, seguidamente, La España democrática y Europa (López Pina 1977); y más teórico, Poder y clases sociales (López Pina 1978). José [Pepín] Vidal Beneyto escribe su interpretación personal en Del franquismo a una democracia de clase (1977). Algunas revistas - como Papers, a la sazón dirigida imaginativamente por Benjamín Oltra- dedican números monográficos al tema como El régimen franquista (Oltra ed. 1978).

En el exterior la reflexión es también importante. Aparece pronto Spain in Crisis (Preston ed. 1976). José M. Maravall publica Dictatorship and Political Dissent: Workers and Students in Franco's Spain (1978). Juan J. Linz publica en la misma fecha un libro pensado a lo largo de los años de su docencia: The Breakdown of Democratic Regimes (Linz 1978), que tiene que esperar nueve años para ser publicado en España como La quiebra de las democracias (Linz 1987). Pero hay poco análisis comparativo con otras sociedades, salvo en Cambio social en la Europa mediterránea (J. M. de Miguel ed. 1979). Los estudios comparativos aparecen con más intensidad en los años ochenta y noventa.

El segundo lustro de la década llama la atención por la concentración de estudios sobre la realidad social española pero en sectores sociales determinados. No es sorprendente que se genere un interés cada vez mayor por el tema del nacionalismo. Se acaba de publicar en el exterior el libro Basque Nationalism (Payne 1975). Varios sociólogos españoles —José Jiménez Blanco, Manuel García Ferrando, Eduardo López Aranguren y Miguel Beltrán- acometen el análisis de una encuesta sobre La conciencia regional en España (1977), que es un estudio básico sobre el tema.

Se observa al final de la década un renovado interés por la estructura social y de clases. Un estudio empírico imaginativo es Estructura social de las ciudades españolas (Martín Moreno y A. de Miguel 1978). Un estudio excelente, imprescindible de consultar en este área de estudio, es el libro de Esteban Pinilla de las Heras sobre la estructura social de Cataluña, Estudios sobre cambio social y estructuras sociales en Cataluña (1979), quizás el mejor estudio sociológico sobre esa Comunidad Autónoma. Aparecen en torno a la misma fecha dos libros de Víctor Pérez Díaz bastante solapables: Clase obrera, partidos y sindicatos (1979) y Clase obrera, orden social y conciencia de clase (1980). Sigue preocu- 
pando tanto la ciudad como el campo, pero se producen estudios imaginativos y críticos; dos de los mejores son Madrid culpable, de Juan Salcedo (1977), y La evolución del campesinado en España, de Eduardo Sevilla Guzmán (1979).

Un área novedosa de investigación es la sociología de las organizaciones. Una de las contribuciones mejores es la de Alberto Gutiérrez Reñón, Estudios sobre la burocracia española (1974). Miguel Beltrán es un sociólogo con una excelente formación internacional que acomete el análisis de La élite burocrática española (1976). Un estudio de caso es Anatomía de una universidad: Para un estudio de sociología de las organizaciones (J. M. de Miguel 1979).

Los temas de juventud y educación interesan con una perspectiva ya más moderna, criticando la reforma educativa de los años setenta. Un estudio extranjero interesante es Manpower and Education in Franco Spain (Horowitz 1979). Alberto Moncada publica estudios llenos de ideas como La adolescencia forzosa (1979), que continúa en Mas allá de la educación (1981). Uno de los libros más populares de la época es Universidad, fábrica de parados (Martín Moreno y A. de Miguel 1979), en donde empieza a preocupar un tema luego explosivo: el paro. Relacionado con todos estos temas se abre una línea de investigación sobre sociología de la ciencia, que hasta finales de los años setenta apenas contribuye con estudios empíricos. Pedro González Blasco es el introductor de este nuevo interés con La comunidad científica española (1979), Historia y sociología de la ciencia en España (1979) y El investigador cientifico en España (1980).

Otra área importante es la sociología de la salud, la medicina y, en general, el sector sanitario. Jesús M. de Miguel contribuye a esta nueva línea de investigación con un análisis comparativo inicial, Health in the Mediterranean Region (1976), que es un estudio comparativo de cuatro países (entre ellos España), y al mismo tiempo un estudio sobre la política interior en La reforma sanitaria en España (1976). El mismo sociólogo publica seguidamente Planificación y reforma sanitaria (1978) y un par de estudios críticos sobre las ideologías de las especializaciones médicas: sobre la ginecología en El mito de la inmaculada concepción (1979) y, unos años después, sobre la pediatría en La amorosa dictadura (1984).

\section{SOCIALDEMOCRACIA}

La sociología española de la década de los ochenta sigue a remolque de los sucesos sociales inmediatos: la transición política, la profundización de la democracia, el proceso de descentralización y los nacionalismos. Salvo excepciones, la mayor parte de la producción sociológica sobre la realidad española se dedica a estos temas; incluso la que se produce en el extranjero sobre España. El objetivo no es tanto analizar Franco y el franquismo, sino las dificultades en la transición democrática, las similitudes con otros países de la Europa meridional y Latinoamérica, los conflictos internos, y los problemas de la socialdemocracia. Es una década (a partir de 1982) con un Gobierno socialista en el poder, una experiencia esperada durante mucho tiempo por generaciones 
de españoles/as con una mezcla de deseo y temor. La experiencia dura casi tres lustros, desde 1982 hasta 1996.

Esta década democrática se abre con un par de estudios en el extranjero que sugieren el pulso de los intereses científicos mutuos. El norteamericano Stanley Brandes se interesa por la masculinidad y el sexo de los andaluces en su excelente estudio Metaphors of Masculinity (1980, 1991); mientras tanto, el sociólogo español Manuel Castells se preocupa de la crisis económica norteamericana en The Economic Crisis of American Society (1980). Casi por vez primera se cruzan intereses entre dos países. Al mismo tiempo, en Francia se publica Les catholiques dans l'Espagne franquiste (Hermet 1980). Mientras tanto, dentro de España preocupa La deserción universitaria (Latiesa 1980). Pero el tema inicial con más pujanza al inicio de la década es el de las migraciones en sus dos vertientes. Por un lado, está la migración al extranjero y su retorno en La emigración española en la encrucijada (Castillo 1980) y en Emigración y retorno (Cazorla ed. 1981). Pero también interesa, casi por vez primera, el caso de la población inmigrante en España (Solé 1981, 1984, 1991).

El cuarto Informe Foessa es peculiar porque se publica en dos partes: son dos gruesos volúmenes, uno en 1981 y el otro en 1983. El primer estudio está dirigido por Juan J. Linz y se dedica íntegramente al cambio político, datándolo entre 1975 y 1981. Es como si ese Informe Foessa quisiera desquitarse de que los tres primeros Informes obvian un tema absolutamente central: la política. Todo el volumen está dedicado a la transición política y las primeras elecciones en España. Contiene datos inapreciables. El segundo volumen (1983) es sobre el cambio social en España 1975-1983, y consta de cinco estudios independientes encuadernados juntos. El volumen primero es seguramente el estudio más importante que existe en España sobre la estructura política del país. Está lleno de ideas, datos, hipótesis, teorías. Es un documento esencial en el análisis del poder.

Desde el extranjero, Juan J. Linz inaugura la década con otros estudios dirigidos al análisis de los problemas de la transición política. Trata el nacionalismo vasco en "The Basques in Spain: Nationalism and political conflict in a new democracy» (1980). El tema lo retoma luego, y directamente en castellano, en el libro Conflicto en Euskadi (1986). Le interesan también los partidos políticos, publicando tempranamente "The new Spanish party system» (Linz 1980), que complementa con un volumen editado junto con José R. Montero, Crisis y cambio: Electores y partidos politicos en la España de los años ochenta (1986). Pero lo significativo es la visión de conjunto que se ofrece de la política española en tres contribuciones: el artículo "A century of politics and interests in Spain" (Linz 1981), otro artículo sobre "A sociological look at Spanish communism» (Linz 1981) y en el libro en castellano España: Un presente para el futuro (Linz 1984). La contribución de Linz sobre la estructura social y política española se conoce cada vez más dentro del país a través de las traducciones de los años ochenta, aunque no incluyen más que una pequeña parte de su producción sobre the case of Spain. 
Hay otras visiones globales realizadas desde el extranjero. Paul Preston publica El triunfo de la democracia en España (1986). Algunas contribuciones son variadas, como en Spain in the 1980's: The Democratic Transition and a New International Role (Clark y Haltzel eds. 1987). Richard Gunther y otros/as colegas desarrollan una atención especial por el caso español. Es importante el libro Spain After Franco: The Making of a Competitive Party System (Gunther, Sani y Shabad 1988) y, también, Politics and Culture in Spain (Gunther 1988). A mitad de la década aparece, en inglés, Spanish Catholicism (Payne 1984).

Hay múltiples memorias políticas y visiones históricas de los años de la transición. Aquí interesan las interpretaciones fundamentalmente sociológicas sobre la transición política, como la de José M. Maravall, La política de la transición 1975-1980 (1981). Hay análisis del cambio de valores de la población en España, entre la apatía y el cambio social (Andrés Orizo, 1983). Se edita una coetánea sobre Transición a la democracia en el sur de Europa y de América Latina (Santamaría ed. 1982). Otros libros colectivos estudian en detalle la transición política hacia el final de la década, con una perspectiva sobre lo ocurrido: La transición democrática española (Tezanos, Cotarelo, y de Blas 1989). Una visión global, que supera el enfoque excesivamente político de otros análisis, es el imaginativo libro editado por Benjamín Oltra, Dibujo de España (1987).

El tema de sociología política se complementa con el análisis del nacionalismo - y de los nacionalismos en España-, que preocupa crecientemente en la dos últimas décadas del siglo. El libro ad hoc es La conciencia regional en el proceso autonómico español (E. López Aranguren 1983), además de la contribución sobre regionalismos y autonomías de Manuel García Ferrando (1982). Del mismo año es un librito más teórico, Once tesis sobre la cuestión nacional en España (Mercadé, Hernández, y Oltra 1983). Una coetánea esencial es Estructuras sociales y cuestión nacional en España (Hernández y Mercadé eds. 1986). Sobre el caso catalán, el análisis ideológico mejor informado durante la década es La ideología nacional catalana (Oltra, Mercadé, y Hernández 1981). El caso vasco aparece bien desarrollado por la pluma del catedrático en Lejona, Alfonso Pérez Agote, La reproducción del nacionalismo: El caso vasco (1984), El nacionalismo vasco a la salida del franquismo (1987), y el libro más teórico sobre Sociología del nacionalismo (Pérez Agote ed. 1989) y también en 1990.

Pero no todos los análisis sobre España en esta década de los ochenta están dedicados a lo político. Vuelven otra vez a estar de moda líneas de investigación antiguas — de los años cuarenta y cincuenta- pero con perspectivas más críticas y globales, revisando lo realizado por los/as colegas anteriores a la luz de una sociedad democrática y europeísta. Dos áreas de interés renovado son la sociología de la familia y la demografía. Salustiano del Campo, quien ya había iniciado (al final de los años cincuenta y en la década de los sesenta) algunos de esos estudios en España, vuelve en los años ochenta a investigar y escribir sobre el tema en La evolución de la familia española en el siglo XX (del Campo 
1982), Análisis sociológico de la familia española (del Campo y Navarro 1985) y La nueva familia española (del Campo 1991). Una posición más crítica es el libro editado por Rosa Conde, Familia y cambio social en España (1982). Julio Iglesias de Ussel inicia temas nuevos como el de Infancia y sociedad en España (1983), Sociología del noviazgo en España (1987), y sobre un área polémica como Las familias monoparentales (1988). Iglesias de Ussel introduce nuevas perspectivas sobre la cambiante situación española, siendo un sociólogo imaginativo y prolífico.

Los temas demográficos cuentan en esta década con un librito polémico de Amando de Miguel, Diez errores sobre la población española (1982), que es útil para entender algunos de los debates estructurales. Un estudio metodológicamente muy elaborado suyo es España cíclica: Ciclos demográficos y generaciones demográficas en la sociedad española (A. de Miguel 1987), que sin embargo tiene poco impacto en esos años. Hay también algunos primeros estudios sobre Políticas de población (Díez Nicolás y J. M. de Miguel 1985) con una perspectiva comparada entre países. Hacia el final de la década, los/as demógrafos superan la posición ideológica tradicional del Instituto Balmes de Sociología y, a partir del nuevo Instituto de Demografía del CSIC, en Madrid, realizan estudios interesantes. Margarita Delgado publica La fecundidad en España desde 1975 (1989) y también un estudio de matrimonios con Juan Antonio Fernández Cordón en ese mismo año. También publica, entrada la siguiente década, Las pautas de nupcialidad en España y sus diferencias regionales (Delgado 1991).

La sociología de la salud continúa el amplio desarrollo de los años setenta con estudios detallados sobre la situación española en La sociedad enferma: Las bases sociales de la política sanitaria española (J. M. de Miguel 1980) y en un pequeño libro sobre la Estructura del sector sanitario (J. M. de Miguel 1983). Una visión empírica global aparece en La salud pública del futuro (J. M. de Miguel 1985) y en Salud y sociedad (J. A. Rodríguez 1987). Por vez primera se analiza sociológicamente una profesión sanitaria que no es la médica en La profesión farmacéutica (J. M. de Miguel, y Salcedo 1987). Las interrelaciones de la política sanitaria española como continuación de La sociedad enferma pueden verse publicadas en Salud y poder (J. A. Rodríguez, y de Miguel 1990). El deporte y la sociología del deporte es una nueva especialidad que impulsa Manuel García Ferrando con estudios como Deporte y sociedad (1982; ver también 1986, 1990).

A caballo entre unos temas y otros se desarrolla la sociología de las profesiones con un estudio general sobre Sociología de las profesiones en España (Martín Moreno, y A. de Miguel 1982), que sirve a partir de entonces de referencia. Hay un estudio excelente de caso realizado por Mauro F. Guillén (español, profesor en Estados Unidos, primero en el MIT y luego en la University of Pennsylvania) titulado La profesión de economista (1989) sobre el caso español. Estos intereses permanentes conectan con la polémica de las clases medias, de la que se vuelve a publicar otro libro hacia el final de la década: $L a$ sociedad de clases medias (del Campo 1989). 
Hay un tema nuevo que tiene importancia creciente en el mundo, y también en la sociedad española. Es lo que se denomina, un poco confusamente, «nuevas» tecnologías. El sociólogo español Manuel Castells, investigando entre Berkeley y Cantoblanco, desarrolla este tema ya desde 1986 en su libro El desafío tecnológico: España y las nuevas tecnologías. Publica, además, Nuevas tecnologías, economía y sociedad en España (Castells et al. 1986) y, en inglés, The Informational City (Castells 1989). Su obra magna es la trilogía La era de la información, que se empieza a traducir a partir de 1997 en Alianza Editorial. Sus estudios tienen un impacto importante en España, pero apenas tiene seguidores al mismo nivel de investigación.

No se puede pasar por alto en esta década uno de los estudios más imaginativos y que mayor impacto tiene en buena parte de sociólogos/as y estudiantes de sociología. Se trata de La organización del desgobierno, de Alejandro Nieto (1984), cuya hipótesis es que la desorganización del Estado español es anterior a Franco. Una docena de años después realiza una segunda versión del libro en La "nueva» organización del desgobierno (1996), en que añade la hipótesis de las contraorganizaciones. Es analizado y criticado sociológicamente en El mito de la sociedad organizada (J. M. de Miguel 1990). Nieto alcanza la celebridad con su libro Corrupción en la España democrática (1997). Se pone de moda en esta década el análisis organizativo y, más globalmente, la idea de $E l$ corporatismo en España (Pérez y Giner eds. 1988). Víctor Pérez Díaz desarrolla algunas ideas comunes en sus diferentes libros sobre la sociedad civil, que se publican a caballo entre las dos décadas. Su primer libro de la serie es El retorno de la sociedad civil (1987), que se subtitula "Respuestas sociales a la transición política, la crisis económica y los cambios culturales de España». Las ideas se desarrollan luego con más claridad en La primacía de la sociedad civil (1993), The Return of Civil Society (1993) y en La esfera pública y la sociedad civil (1997).

Al final de la década se publica una revisión del cambio de valores en la nueva democracia, por José Juan Toharia: Cambios recientes en la sociedad española (1989), que se complementa con su estudio La mitad de la explosión: La población española en perspectiva comparada (Toharia 1989). Aparecen nuevos estudios de sociolingüística como La cárcel de las palabras (J. M. de Miguel, y Moyer 1988). En estos años es bastante activa una Fundación que se preocupa de realizar estudios sobre valores, y particularmente sobre jóvenes, religiosidad y temas educativos. Es la Fundación Santa María (SM), que, impulsada por el sociólogo Pedro González Blasco, publica estudios empíricos útiles para conocer la realidad social española: Jóvenes españoles 89 (1989), Los valores de los niños españoles 1992 (1993), La sociedad española de los noventa y sus nuevos valores (Villalán, Basterra, y del Valle 1992), Religión y sociedad en la España de los noventa (González Blasco y González Anleo 1992), El profesorado en la España actual (González Blasco y González Anleo 1993) y Jóvenes españoles 94 (Elzo et al. 1994) son algunos de los informes. Es parte de un renovado interés por temas de jóvenes, a los que se dedican también otras 
sociólogas como en Los jóvenes ante el sistema educativo (Latiesa 1991). Con este interés por los "presupuestos mentales» de la juventud española - otra juventud diferente a la de los años cincuenta - se sitúa la investigación en la última década del milenio.

\section{ÚLTIMA DÉCADA DEL SIGLO XX}

Las investigaciones sociológicas sobre España en la década de los noventa no proporcionan una idea de fin du siècle ni de fin de milenio. Más bien parece que la sociedad española ya está instalada en el siglo XXI. Hay en esta década más insistencia en lo nuevo que en el propio siglo Xx. The new Spain es un tópico "nuevo" que sustituye al The case of Spain de décadas anteriores. El año 2000 no llama apenas la atención, aunque sí se observa una cierta recapacitación sobre el centenario de la generación de 1898 y su significado. Pero los tópicos no son ya la decadencia de España, sino el desarrollo de la Unión Europea y de los nacionalismos periféricos tardíos. Las dos Españas, después ocho... se convierten en diecisiete.

No hay estudios sobre los problemas de España hacia el año 2000, salvo el quinto Informe Foessa, Informe sociológico sobre la situación social en España, que significativamente se subtitula Sociedad para todos en el año 2000, combinando la idea del 2000 con la disminución de las desigualdades sociales. Por una lado, hay una eclosión de estudios sociológicos globales, nada menos que 19. El resto de la producción sociológica sobre España se dispersa en diferentes temas, sin que puedan establecerse dos o tres tendencias. La profesión sociológica es ya lo suficientemente grande y distribuida regionalmente ${ }^{29}$. La calidad de los estudios sociológicos es considerable, y la necesidad de la aportación extranjera para entender la sociedad española disminuye.

Los 19 estudios sociológicos globales abarcan toda la década. En el año 1990 se crea el CIRES - Centro de Investigaciones sobre la Realidad Social-, financiado por la Fundación BBV, Bilbao Bizkaia Kutxa, y Caja de Madrid. Juan Díez Nicolás es el sociólogo que dirige y realiza los informes anuales en base a encuestas mensuales que analizan los temas esenciales de la estructura social y los procesos de cambio. Los informes se denominan La realidad social en España. El primero se refiere a 1990-1991 y se publica en 1992. Se publican volúmenes además en 1993, 1994, 1995, 1996 y 1997, todos ellos con un banco de datos anexo. Representan el esfuerzo privado más importante de la década por hacer accesibles a la población los datos reales de las encuestas. Desgraciadamente, la experiencia termina en la década. Los temas, que suponen una encuesta mensual, cubren un amplio abanico de temas de estructura social, y problemas sociales y cambio.

29 Además de la tradicional Universidad Complutense (en Madrid), hay estudios de licenciatura de sociología ya en Alicante, Granada, Salamanca, A Coruña, Bilbao (Deusto), Lejona (Universidad del País Vasco), Pamplona, Valencia, y en dos Universidades de Barcelona. 
En 1992 empieza también una serie de análisis globales anuales titulados La sociedad española, siendo el primero el de 1992-1993. Están realizados por Amando de Miguel y su equipo, y financiados por la Fundación General de la Universidad Complutense. Aparecen en la década por lo menos cuatro gruesos volúmenes: en 1992, 1994, 1995 y 1996. Otra serie similar, pero más corta, es la del Centro de Estudios del Cambio Social (dirigido por José M. Martín Patino), que publica España 1993 (CECS 1994) y España 1994 (CECS 1995). El quinto Informe Foessa realiza la encuesta en mayo-junio de 1993, pero se publica en 1994. Aparece una síntesis al año siguiente (González Blasco 1995). Representa el esfuerzo económico e investigador más importante de toda la serie.

Otros estudios sociológicos globales sobre España son algo más puntuales, pero igualmente interesantes. Aparece pronto en la década España: Sociedad y política (Giner ed. 1990). Al año siguiente se publica España a debate, en dos volúmenes (Vidal Beneyto ed. 1991), uno sobre la política y otro sobre la sociedad. La fórmula es ya repetitiva. En ambos estudios cada capítulo está escrito por un especialista diferente. La calidad e interés varía, pero como informes globales suponen — como los demás- una fuente inapreciable de información. La Fundación BBV apoya también un informe en tres volúmenes denominado Tendencias sociales en España, dirigido por Salustiano del Campo (1993). En el mismo año, Richard Gunther edita el libro Politics, Society, and Democracy: The Case of Spain (1993), que aparece como un homenaje explícito a Juan J. Linz. Contiene contribuciones excelentes. En 1994, el Instituto Nacional de Estadística publica un anuario que es algo más que una recolección de estadísticas sociales sobre España, que se titula Panorámica social de España. Es una buena fuente de información sociológica de los propios datos estadísticos del INE.

En el año olímpico de 1992, Ian Gibson publica una visión personal sobre España titulada Fire in the Blood: The New Spain, cuyo título obviamente no se traduce literalmente en la edición española, que prefiere titularse simplemente como España $(1992,1993)^{30}$. En el exterior se publican otros estudios sobre la «nueva España»" ${ }^{31}$ como el librito de Kenneth Maxwell y Steven Spiegel, The New Spain: From Isolation to Influence (1994). El título lo dice casi todo, y es un resumen documentado de la transición. Aparece por fin una biografía importante sobre Franco, realizada por Paul Preston, Franco, a Biography (1993), que es también de obligada consulta. Se observa en el interior una cierta vuelta a explicar y analizar cómo era la España del siglo XX. Amando de Miguel, con fina inteligencia, publica varios libros en esta dirección: Cien años

${ }^{30}$ El libro de Roland Fraser se edita en inglés como Blood of Spain (1996). Es curiosa esa obsesión británica por la sangre.

31 El término "nueva» es absurdo y tiene reminiscencias fascistas que, obviamente, los autores no quieren darle. Se refieren, claro está, a la España democrática de los años setenta (1976) en adelante. Pero la expresión "nueva España» (además de un periódico asturiano) es utilizada profusamente por el franquismo, sobre todo en los primeros años. 
de urbanidad (1991), La España de nuestros abuelos (1995) y Autobiografía de los españoles (1997), este último con una interesante metodología biográfica ${ }^{32}$.

Preocupa el cambio de valores que se produce en la población española. En el fondo, los/as investigadores sociales tratan de averiguar los rastros no democráticos o autoritarios que los cuarenta años de dictadura han dejado en los españoles/as. Una excelente interpretación con datos del Centro de Investigaciones Sociológicas es la de María Luz Morán y Jorge Benedicto, La cultura política de los españoles (1995). También se publican los estudios de Los nuevos valores de los españoles (Andrés Orizo 1991) y el de Sistemas de valores en la España de los años noventa (Andrés Orizo 1996). España participa en la Encuesta Mundial de Valores a través del profesor Ronald Inglehart y gracias al entusiasmo de Juan Díez Nicolás. Además de un libro general de Inglehart traducido al castellano (1991), se publica el voluminoso estudio Tendencias mundiales del cambio en los valores sociales y políticos (Díez Nicolás e Inglehart 1994). La encuesta mundial de 1995 se aplica en España, por varios equipos dirigidos por Juan Díez Nicolás, con muestras nacional y en diversas Comunidades Autónomas, representando un elemento de información valiosísimo de cara al futuro.

Un tema importante dentro de valores es el del nacionalismo, que en los años noventa se convierte en un tema polémico. Un excelente estudio es el de Juan Díez Medrano, Divided Nations: Class Conflict, Political Structure, and Nationalism in the Basque Country and Catalonia (1995). El equipo de sociólogos compuesto por Manuel García Ferrando, Eduardo López Aranguren y Miguel Beltrán publican un análisis de encuesta en La conciencia nacional y regional en la España de las autonomías (1994). También se publica el estudio sobre Nacionalismo y lengua (Tejerina 1992).

La Política — con mayúsculas — da paso en esta década también a un análisis de las políticas (con minúsculas) siguiendo la distinción tradicional entre politics and policies. A un nivel elevado está la contribución de Juan J. Linz, "Rethinking state and regime: Southern Europe's transition to democracy" (1990), el artículo seminal "Transitions to democracy (1990), la discusión sobre "State building and nation building» (Linz 1993) y, posteriormente, el libro Problems of Democratic Transition and Consolidation (Linz y Stepan 1996) ${ }^{33}$. La transición política produce otros análisis interesantes, más en la línea de la elección racional, como el de Game Theory and the Transition to Democracy: The Spanish Model (Colomer 1995). Se realiza también una revisión de la política socialista que abarca desde 1982 hasta 1996 . Un buen análisis (aunque incompleto por la fecha en que se publica) es el de «Democracia y

32 Amando de Miguel realiza una contribución sociológica impresionante, y de calidad, sobre España, con una gran capacidad de innovación y crítica. Es el autor (además de hermano) que considero más decisivo para entender sociológicamente el siglo Xx español.

33 Otras contribuciones importantes de Linz en esos años son Between States: Interim Governments in Democratic Transitions (Shain y Linz 1995) y Sultanistic Regimes (Chahabi y Linz 1997). 
socialdemocracia: Quince años de política socialista en España» (Maravall 1991). Una coetánea más amplia es la de Comportamiento político y electoral (del Castillo ed. 1994). Dos excelentes estudios publicados en el extranjero cubren el tema de sindicatos y empresarios en España. El primero es WorkingClass Organization and the Return to Democracy in Spain (Fishman 1990, 1996). El segundo es Business and Democracy in Spain (Martínez 1993). El tema de empresarias es investigado novedosamente en Mujer y management (Casas 1998).

El tema de investigación más interesante en estos años es la relación entre política y economía; concretamente, entre el régimen político y las políticas económicas. Se realizan varias evaluaciones sociológicas de estas relaciones. Hay estudios comparativos como Economic Reforms in New Democracies (Bresser Pereira, Maravall y Przeworski 1993) y Los resultados de la democracia: Un estudio del Sur y el Este de Europa (Maravall 1995). El punto de vista comparativo dentro del Mediterráneo, pero incluyendo las dos orillas, es el de Jordi Caïs, El desarrollo invisible (1998). El mismo sociólogo publica un manual de Metodología del análisis comparativo que incluye un artículo de Félix Requena sobre «Desarrollo y valores culturales de la población: Comparación de España y Estados Unidos» (en Caïs 1997). Otro excelente análisis sobre las relaciones política/economía es Partidos políticos, crecimiento e igualdad (Boix 1996). Está también el excelente estudio de Laura Chaqués sobre la política farmacéutica española: Políticas públicas y democracia: Análisis de las relaciones entre Estado e industria farmacéutica en España (1999). Hay también estudios de crítica al Gobierno socialista — con más ideología que datos- como el de Víctor Pérez Díaz en España puesta a prueba $1976-1996$ (1996). Varios estudios sobre desigualdades sociales y económicas son auspiciados por la Fundación Argentaria en sendos congresos en Madrid en 1993 y 1994. Con la llegada de la derecha al Gobierno el interés por financiar estudios de desigualdades sociales con dinero oficial disminuye drásticamente, aunque se realiza un tercer congreso en 1997. El siglo se cierra con otro análisis global de la estructura social española y de los procesos de desigualdad en el análisis de Jesús M. de Miguel, Estructura y cambio social en España (1998).

Los estudios de política/economía se complementan con un giro fructífero de la sociología de las organizaciones, que comienza a publicar estudios concretos. La revisión general del campo de investigación aparece en Organizaciones y profesiones (J. A. Rodríguez, y Guillén eds. 1992). Un análisis comparativo que incluye España es el excelente estudio de Mauro F. Guillén, Models of Management: Work, Authority, and Organization in Comparative Perspective (1994). Uno de los mejores estudios de casos es el de la ONCE (Organización Nacional de los Ciegos de España), que Roberto Garvía Soto publica como En el pais de los ciegos: La ONCE desde una perspectiva sociológica (1997). Otro, estudio de organizaciones y trabajo es el de Xavier Coller, La empresa flexible (1997). Un tema que concentra atención por primera vez desde la sociología y la investigación social es el de la Policía. Manuel Martín publica dos libros 
importantes sobre el tema, La profesión de policía (1990) y Mujeres policía (1994). Un estudio de caso sobre una organización policial — verdadero poder azul — es el de Diego Torrente, La sociedad policial: Poder, trabajo y cultura en una organización local de policía $(1997)^{34}$. Un replanteamiento de la sociología de las organizaciones en España, con una crítica a los trabajos de Alejandro Nieto sobre la organización del desgobierno $(1984,1996)$, aparece en El mito de la sociedad organizada (J. M. de Miguel 1990).

Continúa una tradición de estudios demográficos que desentrañan algunas de las cuestiones más importantes sobre la situación española. Juan A. Fernández Cordón publica Demografía, actividad y dependencia en España (1995). Por fin se analiza el impacto de las epidemias, sobre todo de la pandemia de 1918 conocida como "la gripe española», con el estudio de Beatriz Echeverri (1993). Se publica La mortalidad infantil española en el siglo XX (Gómez Redondo 1992). Empiezan ya a acumularse datos suficientes sobre el problema de la nueva inmigración africana en España en libros como La inmigración en Espana 1980-1990 (Izquierdo 1992) y La inmigración inesperada (1996), el estudio más cualitativo de Inmigrantes en España (Ramírez Goicoechea 1996) y el de Ubaldo Martínez Veiga, La integración social de los inmigrantes extranjeros en España (1997). El tema demográfico que concentra más atención es el proceso de envejecimiento de la población, que en España es acelerado, teniendo en cuenta la baja natalidad y el alargamiento de la esperanza de vida (sobre todo en las mujeres). Envejecimiento es un área de máximo interés. Un estudio básico es La sociedad anciana (Bazo 1991), y otro es Envejecimiento y sociedad (M. Teresa Algado 1997). Una visión cualitativa interesante es La ancianidad del futuro (Bazo 1992), que incluye historias de vida de ancianos/as según edades. Los datos básicos sobre el proceso de envejecimiento aparecen en Envejecimiento y familia (J. A. Rodríguez 1994). María Teresa Bazo, quien impulsa esta nueva área de interés desde la sociología, coordina un número extraordinario de la Revista Española de Investigaciones Sociológicas (REIS) sobre sociología de la vejez (Bazo ed. 1996). Servicios sociales y política social es un área que hasta esta década está en manos de trabajo social o economía, pero su interés es creciente en sociología. Demetrio Casado, quien décadas anteriores inicia los análisis de pobreza, avanza en varios de esos temas con Introducción a los servicios sociales (1991), Panorámica de la discapacidad (1991) y Organizaciones voluntarias en España (1992). Se puede ver también Estructuras de la prevención de deficiencias (Collado, Domínguez, y de Miguel, 1992) y un número doble de la revista Gestión y Análisis de Politicas Públicas sobre «Descentralización de servicios social y sanitarios» (Escandell, y de Miguel eds. 1999).

El análisis de la familia española se convierte en un análisis de «familias» e incluso de no-familias: personas viviendo solas, núcleos monoparentales, personas institucionalizadas. Se puede ver Permanencia y cambio en la familia española (Flaquer y Soler 1990). Un artículo que resume varias de las nuevas ideas

34 Ver también J. M. de Miguel y Martín (1995). 
es el de Julio Iglesias de Ussel y Lluís Flaquer, «Familia y análisis sociológico: El caso de España» (1993). Se publica también una colección de estudios sobre Estrategias familiares (Garrido, y Gil Calvo eds. 1993). Ángeles Valero publica un monográfico extraordinario de la REIS sobre familia que es importante por sus contribuciones (1995). Un excelente libro es el de Julio Iglesias de Ussel sobre La familia y el cambio político en España (1998). Una contribución imprescindible es el libro sobre La nueva familia española (1999), de Inés Alberdi. Conectado con familia, un tema que empieza a interesar es el amistades y asociacionismo. Félix Requena lo analiza para el caso español en base a una metodología novedosa en Redes sociales y mercado de trabajo (1991) y, sobre todo, en Amigos y redes sociales (1994). Para analizar la sociedad española es cada vez más importante realizar un análisis de cohortes. A finales del siglo XX, las diferencias por generaciones son las más grandes de la historia de España. Este tema es investigado en profundidad en el estudio La sociedad transversal (J. M. de Miguel, Castilla, y Caïs 1994) y en Dinámica intergeneracional en los sistemas de valores de los españoles (Andrés Orizo 1995).

Al fin de siglo XX el estudio del sector sanitario es un área ya bien establecida en la sociología española. Juan Irigoyen publica La crisis del sistema sanitario en España: Una interpretación sociológica (1996). La investigación se expande hacia temas más complejos y problemáticos, como las desigualdades sanitarias (Navarro y Benach 1996). España se convierte en el país de Europa con más casos de sida, lo que concentra la atención de diversos sociólogos sobre el sida, como queda documentado en "Spain: An epidemic of denial» (J. M. de Miguel y Kirp 1992) y otros trabajos (J. M. de Miguel 1994, y J. M. de Miguel, Castilla y Caïs 1994). Sobre enfermedad general y rol del paciente (y del médico), un estudio imaginativo y novedoso es el de Omar G. Ponce de León, El médico enfermo (1997). Hay un nuevo interés por investigaciones en torno al cuerpo, cuyas primeras contribuciones se incluyen en Perspectivas en sociología del cuerpo (Bañuelos ed. 1994). Por primera vez también se empieza a analizar la muerte desde una perspectiva sociológica no estrictamente demográfica o estadística: "El último deseo: Para una sociología de la muerte en España» (J. M. de Miguel 1995) y en «El canon de la muerte» (Marga Marí-Klose, y J. M. de Miguel 1999).

La década de los noventa supone una profundización de la investigación sociológica. Se abandonan las tendencias ideológicas extremas de las décadas anteriores y se revisan las hipótesis e investigaciones anteriores sobre familia, demografía, nacionalismo, política, etc. Se incorporan metodología y técnicas nuevas que permiten estudios más cualitativos y en profundidad. Se realizan estudios de observación participante y de comunidad tan interesantes como $\mathrm{La}$ sociedad rosa (Guasch 1991) o Fe en la palabra (García Jorba 1999). Hay un renovado interés por lo minimalista y lo autobiográfico como estrategia para entender la estructura social española. Así puede verse en Andanzas y caminos: Historias de seis familias españolas (López Aller y López-Accotto 1993), en Autolbiografias (J. M. de Miguel 1996) y Echa pan y cubre (J. M. de Miguel 
2000). El nuevo estudio de redes genera estudios tan imaginativos como el de Ruth V. Aguilera sobre «Directorships interlocks in comparative perspective: The case of Spain», realizado desde la Universidad de Harvard (Aguilera 1997), y su tesis doctoral en Harvard (1998). Se ponen de moda los estudios sobre fotografía e imagen, como De la investigación audiovisual (Buxó y J. M. de Miguel eds. 1998). Hay una renovación de los estudios sociológicos sobre lo penal, con el libro Desviación y delito, de Diego Torrente (en Alianza Editorial 1999). María-Ángeles Durán publica el excelente estudio sobre La ciudad compartida: conocimiento, afecto y uso (1998). La sociedad global e informatizada es la última preocupación del siglo, como puede verse en la trilogía de Manuel Castells, La sociedad red (1997-98).

El siglo XX termina con una España que experimenta profundos cambios sociales, y que en seis o siete décadas pasa de una estructura social casi medieval a ser un país plenamente europeo, postindustrial y avanzado. Los cambios sociales que se producen en la segunda mitad del siglo son tan importantes como el cambio de régimen que supone enterrar la dictadura franquista e iniciar una democracia moderna y efectiva. Pero lo que más se transforma en estas cinco décadas es el conocimiento sobre la sociedad española. Se pasa de no saber prácticamente nada de cómo es y qué sucede en España, a una sociedad en que abundan las investigaciones sociólogicas de calidad sobre la realidad social. Al final del siglo XX existe una treintena de (voluminosos) estudios sociológicos globales, imprescindibles para entender la sociedad española ${ }^{35}$. La sociología deja de ser un arma arrojadiza con objetivos ideológicos para participar en un conocimiento racional y moderno de la nueva organización social. La sociedad española es cada vez más compleja, e incluye problemas sociales que son complicados de solucionar. La eclosión de estudios sociológicos sobre España, y la transformación en una sociedad progresista y competente, es el reto más optimista de la sociología desde su nacimiento hace siglo y medio.

\section{DEBATES SOBRE ESPAÑA}

Las investigaciones sociológicas no ocurren en el vacío. Su publicación genera desacuerdos, críticas y, a menudo, polémicas. Algunas son tan importantes en la tradición sociológica como la propiedad privada es un robo, zorros o leones, la ley de hierro de la oligarquía, la religión protege por ser sociedad, la neutralidad valorativa, el malestar de la cultura, el Teorema de Thomas, la ética protestante lleva al espíritu del capitalismo, o el principio Mateo. En España hay polémicas sociales desde hace muchos años. Precisamente uno de esos debates es que a los/as españoles les gusta polemizar, adoptar posturas maniqueas, ser intolerantes y asegurar que son capaces de perder la vida por

${ }^{35}$ Un análisis de esos estudios globales aparece en Jesús M. DE Miguel, Estructura y cambio social en España (Madrid: Alianza Editorial, 1998), 681 pp. 
sus ideas. Pero la mayoría de los debates sociales antes de la Guerra Civil (1936-1939) no se plantean como objetos de análisis sociológico, ni se realizan estudios empíricos sobre los mismos. Son polémicas interesantes, pero que no producen —en su tiempo- datos ni un análisis sociológico riguroso, y que no impregnan las discusiones posteriores.

Hay que tener en cuenta que algunas son polémicas heredadas de antes de la Guerra Civil, e incluso provienen de siglos anteriores. Por ejemplo, la polémica de la pobreza en España es bastante antigua. La tradición picaresca española mantiene que la pobreza agudiza el ingenio, incrementa la inteligencia y la innovación. Se refiere a la pobreza digna o la pobreza frente a la explotación social. A menudo su justificación como polémica aparece en parejas, como el lazarillo (de Tormes) y el ciego, Rinconete y Cortadillo, el hidalgo Alonso Quijano el Bueno y el labrador Sancho Panza. Ya en el siglo XVIII llama la atención la extrema pobreza en algunas regiones de España, y muy especialmente en las Hurdes. Se produce una visita real —de Alfonso XIII - a la región en junio de 1922 y, una década después, un impresionante documental, Tierra sin pan, de Luis Buñuel, originalmente en francés (Marañón et al. 1993). Curiosamente, tanto Las Hurdes (en los años veinte), como Deleitosa (en los años cincuenta), que representan dos de las polémicas más importantes sobre España, se producen en Extremadura ${ }^{36}$. El tema de la pobreza no termina con el desarrollo económico, sino que sigue generando debates interesantes en los años sesenta y noventa del siglo XX.

Otras polémicas antiguas son bien conocidas, analizadas por historiadores y críticos literarios. Por ejemplo, está la polémica de que el descubrimiento de América es un mito. España no descubre América. Cuando llegan los descubridores ya había habitantes en ese continente. Se afirma que la labor colonizadora española no es civilizadora ni evangelizadora, sino destructora de las culturas americanas autóctonas ${ }^{37}$. De la misma época es la polémica de que el honor es el valor más importante del mundo. El tema domina luego los siglos XVI y XVII, y se populariza en el teatro, con obras como El médico de su honra, El alcalde de Zalamea, o Fuenteovejuna. El honor es en ese debate social el principal factor estructurante de la sociedad, incluso por encima de la propiedad privada. Aunque en realidad su objetivo es distraer la atención sobre el tema central, que es la repartición de la propiedad agraria.

${ }^{36}$ El MEIAC, Museo Extremeño e Iberoamericano de Arte Contemporáneo, incorpora, al fin del siglo XX, exposiciones antológicas y excelentes sobre Luis Buñuel (Hurdes) y W. Eugene Smith (Deleitosa) que resultan imprescindibles para entender ambas polémicas. Hay que agradacer a Antonio Franco Domínguez, su director, una visión clara y moderna sobre ambos debates y su decidida contribución.

${ }^{37}$ Véanse, por ejemplo, libros como J. H. Elliott, The Old World and the New, 1492-1650 (Cambridge: Cambridge University Press, 1970); Ulrico SCHMidel, Relatos de la conquista del Río de la Plata y Paraguay 1534-1554 (Madrid: Alianza, 1986), 127 pp.; Alvar NúÑEZ CABEZA DE VACA, Naufragios (Madrid: Alianza, 1989), 181 pp., sobre el año 1542; y Francisco Vázquez, El Dorado: Crónica de la expedición de Pedro de Ursua de Aguirre (Madrid: Alianza, 1987), 171 pp. 
Un debate que se inicia en 1782 es la polémica de la Ciencia. Mantiene que en España no ha habido ni puede haber ciencia, debido al carácter de los/as españoles (los García Camarero, 1970) ${ }^{38}$. Se resume luego en la frase irónica de [don] Miguel de Unamuno de «QQue inventen ellos!». Por la misma razón, tampoco pueden existir las ciencias sociales, pues los españoles/as son incapaces de analizar la realidad social de forma objetiva. Relacionado con ello está la expresión de Antonio Machado de que España es «el rabo por desollar de Europa», en el sentido de que es el territorio más subdesarrollado del continente europeo. Toda una generación de intelectuales convive con la idea de que África empieza en los Pirineos.

La polémica fundamental de la generación del 98 es la decadencia de Espa$\tilde{n} a$. España pierde en el fin de siglo pasado una gran parte de sus posesiones coloniales, lo que produce un espíritu de fracaso político y económico. En realidad es una decadencia ininterrumpida desde que, en tiempos de Felipe II, en España no se ponía el sol. El año 1898 es el momento máximo de reflexión sobre esa decadencia secular anunciada por Ángel Ganivet en Idearium español en 1897, un año antes de suicidarse. Relacionada con esa polémica está la de las dos Españas. Lo que define el carácter de la sociedad española es la exageración y, por lo tanto, la polarización en dos posturas antagónicas: clericales/anticlericales, comunistas y fascistas, rojos/azules, tradicionalistas y progresistas. En el fondo, el tema es la intolerancia. "Una de las dos Españas ha de helarte el corazón», como advierte Antonio Machado a todos los españolitos que vienen al mundo. Pero es una intolerancia reciente, pues en la Edad Media la Península Ibérica era cruce de culturas y religiones. Una polémica un poco más elaborada de la generación de 1914 es la de la España invertebrada. Basada en un famoso libro del filósofo y sociólogo José Ortega y Gasset (de 1921), considera que en España los momentos de crisis aumentan los nacionalismos periféricos. Es una hipótesis que luego se incorpora a los estudios sobre nacionalismo de la segunda mitad del siglo XX.

Sobre la guerra hay variadas polémicas, pero quizás la más interesante es que la Guerra Civil de 1936-39 es inevitable. El tema aparece ya en el planteamiento del laberinto español de Gerald Brenan (1943). Pero no es una polémica que se debata desde la sociología, sino que pasa al debate público, a los/as científicos políticos, historiadores y, sobre todo, a los políticos/as. Francisco Franco mismo genera alguna polémica pero nunca muy estructurada. La dictadura desarrolla tópicos como España unión de destino en lo universal, portadora de valores eternos, defensora de Occidente, por el imperio hacia Dios, o los veinticinco años de paz. Una afirmación que tiene interés demográfico es la insistencia de Franco en sus discursos públicos de que algún día España llegará a tener cuarenta millones de españoles/as. Paradójicamente, en el siglo XX nunca se alcanzan esos cuarenta millones de españoles, pues cuando se está muy cerca

38 Se desencadena por el artículo sobre el tema de Nicolas Masson en la Nueva Enciclopedia de 1782 . 
(como a finales del siglo) la natalidad baja tanto que retrocede el crecimiento de la población. Alcanzar una España con 40 millones es, pues, un reto demográfico curioso.

Pero la mayoría de estos debates no producen análisis sociológicos serios durante el siglo XX (el período de análisis del presente artículo), sobre todo en la segunda parte, que es cuando se desarrolla fundamentalmente la investigación sociológica empírica sobre España. Es posible que en el futuro algunos/as investigadores retomen esas polémicas y generen análisis con datos reales. Por ejemplo, se habla cada vez más de la memoria histórica sobre la Guerra Civil española (siempre refiriéndose a la de 1936-39) y se producen estudios innovadores como el de Ronald Fraser, Recuérdalo tú y recuérdalo a otros (1979, 1996); el de Paloma Aguilar, Memoria y olvido de la Guerra Civil española (1996), o la investigación en marcha de Pau Marí-Klose en la Fundación Juan March. Pero, en general, hay poco analizado empíricamente sobre los debates españoles de siglos pasados.

Se puede aprender bastante de las polémicas sociológicas durante este medio siglo. Algunas son puntuales; otras continúan durante varios años, y reaparecen como guadiana, adoptando formas distintas. Los debates escritos, y de carácter sociológico, más importantes del último medio siglo son numerosos. Correlacionan con los procesos sociales de cambio que se observan en la sociedad española de este siglo, pero no siempre. Eso sugiere que algunos debates son cortinas de humo para no tratar de temas más esenciales de la estructura social y del cambio de la sociedad española. Es, por ejemplo, el caso del tema del «honor» para evitar hablar del tema de la "propiedad». Es posible que los sociólogos/as de la época no identifiquen bien los procesos más importantes, o que incluso no haya sociólogos/as interesados en el tema. Los debates más importantes no siempre producen mejor investigación.

A continuación se enumeran una treintena de las polémicas o debates sobre España que se consideran más importantes. Aparecen en aproximado orden cronológico. Cada uno admite posturas encontradas, opuestas, que definen la polémica con hipótesis diferentes. Todos los debates tienen en común que intentan demostrarse con datos, documentos, estadísticas, tablas. Estos debates no son estáticos, sino que van evolucionando. Aquí sólo se recoge una definición rápida; cada uno de ellos merecería un estudio en profundidad. Pero la comprensión global de los debates más importantes formulados por la Sociología española es en sí mismo un factor explicativo de la estructura y el cambio de la sociedad durante esas décadas.

España es un país desértico, rural y joven. Son en realidad tres debates, pero suelen venir juntos. Es uno de los más antiguos que se heredan al inicio del franquismo. Se suele incluir la idea de que el futuro de España está en su economía agraria. Los valores rurales son los más estimables. El campo está compuesto de familias jóvenes, con alta natalidad, optimistas. Se combina con la polémica antigua de que España es país montañoso y desértico, que difícilmente puede llegar a tener cuarenta millones de españoles. Que seguirá siendo siempre un país desértico. 
España va hacia una sociedad de clases medias. Francisco Murillo Ferrol introduce el tema en 1959, aunque Francisco Fernández Sánchez Puerta inicia el tema previamente en Las clases medias económicas (1951). Salustiano del Campo publica en 1960 un libro titulado Las clases medias y la movilidad social en la sociedad industrial (del Campo 1960), y tres décadas después resume sus ideas en La sociedad de clases medias (1989). José Castillo plantea el tema en 1969 en un artículo, «Las clases medias: ¿mito o realidad?». Se duda que España vaya a tener una clase media extensa similar a la de otros países centroeuropeos. Más bien se diferencia entre «clase media antigua» y «nuevas clases medias». Luego enlaza con la polémica de la sufrida clase media, la que produce el desarrollo. A partir de 1975 (Foessa 3) se critica la teoría de las clases medias por intentar evadir el conflicto de clases sociales.

Las ocho Españas. Es una polémica que comienza con un artículo de Juan J. Linz y Amando de Miguel sobre "Within-nations differences and comparisons: The eight Spains», en 1996, en que se trata de establecer las diferencias de la estructura social en base a dos indicadores: nivel de proletarización y proporción de clase media urbana. La discusión de este modelo que supera la tradición de las dos Españas lleva luego a definir diecisiete Españas (Miguel Beltrán) y veinte Españas (A. de Miguel en el Foessa 2 de 1970).

¿Es España una sociedad de consumo de masas? Relacionado con la polémica anterior, se duda de si España puede adoptar el modelo centroeuropeo de consumo masivo. En ambas polémicas late la duda de si España puede ser (en el futuro) un país similar al resto de los países europeos desarrollados. Es tratado en un artículo con ese mismo título por José Castillo (1966, y también en 1968 y 1987) y Amando de Miguel (et al., en el libro de Alberto Míguez, 1969).

El milagro económico español. España es un caso extraordinario que produce en pocos años un crecimiento económico acelerado. No hay tal milagro, sino una combinación de factores: punto bajo de partida, pluriempleo dentro de España, horas extraordinarias y horarios excesivos, migración al extranjero con envío de dinero a España, control de la población trabajadora, explotación, no participación política. Es un país, además, sin derecho de huelga y con una sindicalización prohibida. Posteriormente los sindicatos siguen siendo débiles. Es una polémica que combina con la del «desarrollo económico y social», que es la crítica fundamental a los Planes de Desarrollo a partir de 1964. Combina con la idea de que, a pesar del milagro económico español, España no está preparada para un cambio político (hacia un modelo de «asociaciones políticas») hasta que supere los mil dólares de RPC. Es el razonamiento que defiende el Gobierno tecnocrático (del Opus Dei) durante la dictadura franquista.

Los efectos no queridos del desarrollo económico. Se refiere al cambio de valores, la desigualdad, el desorden social, incluso la inmoralidad y secularización, el que España se parezca cada vez más a Europa y pierda su identidad. Coincide con el título de un libro de Francisco Guijarro en 1968, animador de los informes Foessa. También aparece a veces como «la incómoda relación entre el 
desarrollo económico y la modernización política» en el capítulo 5 -censurado- del Foessa 2, de 1970.

El descenso imparable de la natalidad. El tema se introduce tempranamente por José Ros Jimeno en 1944, pero la polémica se produce en los años setenta entre Salustiano del Campo (1972; Del Campo y Navarro 1987), Juan Díez Nicolás (1967, 1971) y Amando de Miguel (1974, 1982). Es en 1973 cuando se plantea globalmente la polémica. Está implícito si la población española utiliza realmente métodos modernos de control de natalidad. Por modernos se entiende la píldora anovulatoria. La polémica se desarrolla antes de que realmente baje la tasa de natalidad hasta mínimos históricos y mundiales en los años noventa.

La familia nuclear. Realmente, la familia española no se transforma de familia extensa a nuclear. Ya se propone el tema en Salustiano del Campo (1960), y lo sigue desarrollando en 1982, en S. del Campo con Navarro (1985) y en 1991. No puede ya hablarse de la familia española, ni siquiera de la «nueva» familia española, o del «nuevo modelo de familia», sino de distintos tipos o modelos de familias, e incluso de no-familias (hogares). Se tienen en cuenta las familias monoparentales y los hogares unipersonales. Esta polémica enlaza con la de la reducción del tamaño de familia, retraso en el matrimonio versus no fecundidad y número de hijos/as.

El franquismo es un régimen autoritario y no dictadura. La polémica parte del famoso artículo de Juan J. Linz, "An authoritarian regime: Spain» (1964), traducido al español en 1969 y 1974. El régimen de Franco carece de algunas de las características esenciales de una dictadura: no hay ideología sino mentalidades, no hay movilización, apenas partido único, etc. Es un régimen a caballo entre la democracia y la dictadura, especie de "dictablanda» de la que se supone es posible salir con facilidad. Luego se espera realmente a la muerte del dictador. Pero la polémica vale para diferenciar sistemas políticos, y contribuye considerablemente al avance de la ciencia política.

La movilidad intergeneracional neta es nula. Amando de Miguel, en un artículo en inglés, en 1965, señala que la movilidad social es grande en España en los años sesenta. El Informe Foessa 1 (1966) apoya la misma idea. Se critica luego que existe una movilidad social bruta que depende de la creación de puestos de trabajo de niveles distintos, pero, si se mide bien, en España no hay movilidad social neta. El sistema de estratificación social sigue siendo igualmente injusto o incluso cada vez más desigual. Parte del debate aparece en Juan Díez Nicolás (1972) y Antonio de Pablo en el Foessa 3 (1975).

Teoría del desarrollo como un ballet. España lleva unos años de retraso con relación a Francia o Italia. Basta con que pasen esos años para que España se sitúe al mismo nivel de desarrollo de esos países ahora. La teoría aparece en diversas publicaciones, sobre todo a partir del Foessa 1 y 2 (1966, 1970), y fundamentalmente en los años sesenta. El desarrollo se realiza de forma acompasada, como un ballet, en el que los/as actores avanzan al unísono pero en posiciones diferentes: atrasadas y adelantadas. España siempre irá por detrás, 
conservando diferencias. Pero optimistamente basta con que pasen unos años para que España se desarrolle de forma igual. La solución es dejar pasar el tiempo. Esta hipótesis enlaza con una polémica política franquista de que España no está "preparada" para la democracia, pero que cuando supere los 1.000 dólares de renta per capita es posible que se convierta en democracia.

La socialización de la sanidad es creada por el franquismo, pero la democracia la privatiza. Durante la dictadura franquista se crea un sector sanitario público extenso, que alcanza progresivamente a toda la población y no sólo a los/as trabajadores y sus familias. Algunas personas plantean que la socialización va a producir un deterioro de la medicina y una relación impropia médico/paciente. Insistentemente se habla de un proceso de privatización de la sanidad que no llega a producirse. Llama la atención que en España la sanidad está más "socializada» que el sector educativo. Se confunde el concepto de "socialización» con el de sector público. El debate se inicia a partir del capítulo de sanidad del Foessa 2 (en 1970).

Los cambios demográficos son racionales. Se supone una inteligencia especial de la estructura demográfica para cambiar de tal manera que resuelve otros problemas sociales. Se cree en una cierta idea de que la Naturaleza es sabia. Los cambios demográficos como el retraso en el matrimonio, alto índice de soltería femenina, alargamiento de la esperanza de vida, retraso del baby boom tras la Guerra Civil, familia nuclear, etc., son soluciones a problemas y no generan conflictos. Incluso la distribución de la población en el territorio es "racional» y la mejor solución corológica para una extensión grande de terreno y poca población total. La hipótesis repetida de la racionalidad demográfica aparece fundamentalmente en el Foessa 2, y la teoría corológica es establecida por Román Perpiñá tempranamente (1952, 1954, 1962, 1972). La racionalidad demográfica justifica la no-racionalidad política de las últimas décadas del franquismo, ya en un entorno no-autárquico y desarrollado. Frente a esta hipótesis se plantea el «estancamiento demográfico» (el país decrece en población y envejece) y, a veces, la «economía demográfica» (pocas muertes y pocos nacimientos como una especie de ahorro de esfuerzos demográficos). Es curiosa la insistencia en la racionalidad demográfica cuando no lo es la estructura política, y que no se ponga en duda la legitimidad de la dictadura franquista.

Hay que ir hacia un orden equilibrado de ciudades, según su tamaño. Existe un orden natural prefijado al que se debería tender, una rank-size rule o jerarquización de ciudades. Es similar al de la racionalidad demográfica, pero en este caso urbana. Un gradiente suave es lo adecuado. De paso se defiende implícitamente la capitalidad de Madrid frente a Barcelona. También se consideran que son preferibles las ciudades medias a las metrópolis. Se observa una romantización de esas ciudades provincianas (muchas son capitales de provincia). Se puede ver el inicio de la polémica en García Barbancho (1968), Foessa 2 (1970) y en el Foessa 3 (1975). Late la idea de que la población no es racional en sus movimientos migratorios y la forma de fijar residencia, y que las personas deben ser orientadas. Encubre también un cierto antibarcelonismo. 
La sufrida clase media. La clase social que más contribuye al desarrollo y que proporcionalmente obtiene menos es la clase media urbana. A veces se sustituye por la polémica de que el desarrollo español (el milagro económico español) se logra gracias a la España pobre, tal y como se argumenta en el Foessa 4, en 1983. Es además la clase más conservadora, que supone un nivel de control social más grande sobre sus miembros.

Se está produciendo un proceso de secularización. Baja la práctica religiosa (católica) externa, porque cambian las formas de expresión de la religiosidad. Eso es más visible en las clases altas, cada vez menos religiosas y más egoístas, con una menor natalidad. Pero la población es en el fondo cada vez más profundamente religiosa, o al menos igual. Es un bache temporal, pero España volverá a ser igualmente católica. Se suele combinar con el debate sobre el papel de la Iglesia Católica durante el franquismo y la transición política. Se defiende que la Iglesia Católica española cada vez se distancia más del régimen de Franco, e incluso que es uno de los protagonistas fundamentales para lograr el cambio hacia un proceso de democratización. Se asegura que una extensa parte de la Iglesia Católica se opuso a la dictadura franquista, y que fue la primera defensora de la transición política. En el lado opuesto está la idea de la Iglesia Católica como la gran institución legitimadora de la dictadura franquista.

En las primeras elecciones libres ganará el Partido Comunista. Se entiende que el Partido Comunista va a ser un partido de masas, muy extenso, que será la alternativa constante a un partido de centro-derecha de ideología cristiana. La polémica se inicia en 1967 con un artículo de Juan J. Linz, "The party system of Spain: Past and future», en un libro editado por Seymour M. Lipset y Stein Rokkan (Linz 1967), pero se debate fundamentalmente entre 1976 y 1982, sobre todo a partir de las primeras elecciones generales de 1977. Para el cálculo de los porcentajes se sigue una comparación con la estructura social y política de Italia. Es curioso que algunos líderes políticos actuales (comunistas) todavía creen en esta hipótesis.

El milagro de la transición política. Es parte de la atribución milagrera o peculiar del the case of Spain. Sólo España ha sido capaz de pasar de una dictadura a una democracia sin ruptura ni conflictos graves. Es gracias a la inteligencia y decisión del rey Juan Carlos I, y a la decisión de las élites políticas, muchas de ellas franquistas. Sin embargo, se critican los inventos de Franco del Movimiento como pseudopartido político o la tardía Ley de Asociaciones Políticas, que nunca llegó a ponerse en marcha.

La organización del desgobierno es anterior al franquismo. El Estado en España está organizadamente desorganizado, o desgobernado, siguiendo una pauta que proviene de varios cientos de años. La idea inicial es de Alejandro Nieto (1984). Luego reformula su hipótesis señalando que el sistema crea automáticamente "contraorganizaciones» (Nieto 1996). Pero no analiza por qué se produce ese desgobierno (o desorganización) ni quién sale beneficiado. La crítica a la hipótesis original se plantea en El mito de la sociedad organizada (J. M. de 
Miguel 1990). Nieto plantea luego el tema de la corrupción dentro del sistema democrático español (1997).

La aparente modernidad. La sociedad española muestra a menudo valores que se suponen son modernos, pero que no responden a un análisis serio. Por ejemplo, se consumen muchos anovulatorios o se ponen dispositivos intrauterinos como sistema de control de natalidad. Otra es que la sociedad exagera su estructura urbana en grandes ciudades. La población tiende a comprar vivienda. Hay toda una serie de comportamientos que se presentan como "modernos», pero que unos años después se demuestran como poco progresivos.

Apatía politica y baja participación política. Muestra una cultura política defectuosa de la población española que deriva de la propia dictadura franquista. Ya en el franquismo los estudios sociológicos llaman la atención sobre la supuesta apatía política. La población prefiere no hablar ni leer sobre política. Posteriormente se resalta la baja participación en elecciones, en partidos políticos y en sindicatos. Parte de la discusión se resume en el Informe Foessa 4, de 1981. Por otro lado esa apatía política se atribuye a la reciente institucionalización de la democracia en España (Carolina G. de Miguel 1999).

La sociedad civil es el futuro de la democracia. Insistente hipótesis de Víctor Pérez Díaz planteada de forma algo tautológica: la verdadera democracia es la sociedad civil; así, el futuro de la democracia es el de la sociedad civil. La presenta originalmente en 1987, en el libro El retorno de la sociedad civil, y luego en 1993 y 1997.

El número de pobres aumenta. Tras la polémica de las Hurdes de 1922, la polémica de la pobreza se reinicia en los años sesenta con el éxodo rural a las grandes ciudades. Es el fenómeno nuevo del chabolismo y barraquismo que se denuncia en el Plan CCB y en el Foessa 1, de 1966. La polémica vuelve otra vez en los años noventa con la afirmación de que hay un millón de pobres en España. Los datos se calculan en el Foessa 5 (en 1994). La riqueza crea pobreza y desigualdad. Implícitamente se considera que un sistema democrático-capitalista no puede reducir la pobreza. Es necesario un planteamiento cristiano (de repartición caritativa de los bienes) para resolver el problema. Paralelo a esto es que los servicios sociales encargados a la Iglesia Católica (y sus instituciones como Cáritas) son un sistema bastante más barato y mejor que la labor que puede realizar el Estado.

España es un país no saludable. Es parte de la tradición de la polémica de España como país inhóspito (desértico, montañoso, sin agua), pero que se combina en los años setenta con el «mito de la falta de educación sanitaria de la población». La población tiene que ser educada y debe seguir las órdenes de los/as expertos. En especial, las madres no saben bien lo que hacen y pueden llegar a matar a sus hijos/as. Se cree que la mortalidad es alta, la esperanza de vida baja. No se explica el misterio del excelente nivel de salud de los españoles (sobre todo de las españolas).

Las desigualdades de renta son cada vez mayores. El mercado económico actual y el modelo capitalista llevan indefectiblemente a un aumento de des- 
igualdades de riqueza entre los españoles, las familias y las regiones. La polémica se inicia con el Foessa 4 (1983).

El desarrollo crea inevitablemente desigualdad, pero es una situación temporal. La desigualdad social es el precio pagado por el desarrollo. Hay que ser desiguales durante unos años, con la esperanza de que luego se puedan reducir las desigualdades. Las crisis económicas, paradójicamente, disminuyen algo las desigualdades sociales. A veces se combina con la polémica de que España es un país bastante igualitario o con pocas diferencias sociales.

Los nacionalismos periféricos son inevitables. España es un caso de construcción temprana del Estado, pero con nacionalismos periféricos (tardíos) contra el Estado. La hipótesis originalmente es de Juan J. Linz (1973). Quizás el problema es una construcción demasiado temprana de Estado. A veces se justifica que el problema de la democracia en España es que se plantea demasiado pronto. El nacionalismo conflictivo, e incluso violento, es inevitable en el caso de España. Es parte de la tensión centro-periferia que existirá siempre. Implícitamente se defiende España como un modelo de Estado plurinacional.

La sociedad red es el sistema del futuro. La globalización de la economía (y de los problemas sociales), asociada a la informatización de la sociedad, lleva a que la estructura social sea en forma de red. Incluso el Estado-nación se transforma progresivamente en un sistema de red, para no desaparecer.

Los debates sociológicos no mueren, sino que se acumulan unos sobre otros. Aquí termina el análisis de la contribución de la investigación sociológica sobre la sociedad española, justo al filo del año 2000. El siglo XXI hereda un puñado de debates sociológicos interesantes que cuestionan el cambio de la estructura social española. Como se insinúa al principio del artículo, la Sociología refleja miméticamente las transformaciones de la sociedad. Sería importante empezar a evaluar los cambios reales que ha producido la Sociología en la sociedad española. Pero quizás cien años son pocos — sobre todo los primeros cien- para evaluar apropiadamente esa contribución. Los sociólogos/as del siglo XXI tendrán que realizar esa labor.

\section{ABSTRACT}

Spanish sociology took root and developed in the 20th century. Forty years have passed since the first survey of «Sociology in Spain» drawn up by Enrique Gómez Arboleya. This paper presents the studies of Spanish society conducted inside and outside the country throughout the entire 20th century. The development of Sociology is a process which should be studied parallel to the transformation of the social structure of Spain and processes of social change. The hypothesis is that knowledge reflects society, and at the same time tries to change it. The last part of this paper also contains a summary of the main polemics and sociological debates which have been unleashed in the 20th century. A study of the experiences of social change which have taken place in Spain thanks to Sociology remains to be made. 